\title{
An Analysis of energy-related greenhouse gas emissions in Turkish energy-intensive sectors
}

\author{
Abdulkadir Bektas \\ The Ministry of Energy and Natural Resources, Nasuh Akar Mah. Türk Ocağı Cad. No:2 \\ 06520 Cankaya - Ankara / Turkey
}

\begin{abstract}
In recent decades, greenhouse gas (GHG) emissions have been a critical priority of global environmental policy. The leading cause of the increase in GHG triggering global warming in the atmosphere is the continuously growing demand for universal energy due to population and economic growth. Energy efficiency and reduction of $\mathrm{CO}_{2}$ emissions in highly-energy consuming sectors of Turkey are critical in deciding a low-carbon transition. In this study, the change of energy-related $\mathrm{CO}_{2}$ emissions in Turkey's energy-intensive four sectors from 1998 to 2017 is analyzed based on the Logarithmic Mean Divisia Index (LMDI) method. It is used to decompose $\mathrm{CO}_{2}$ equivalent emissions changes in these sectors into five driving forces; changes in economic activity, activity mix, energy intensity, energy mix, and emission factors. Analytical results indicate that economic activity is a vital decisive factor in determining the change in $\mathrm{CO}_{2}$ emissions as well as sectoral energy intensity. The activity effect has raised $\mathrm{CO}_{2}$ emissions, while energy intensity has decreased. This method indicates that the impact of the energy intensity could be the first key determinant of GHG emissions. Turkey's efforts to be taken in these sectors in adopting low carbon growth policies and reducing energy-related emissions to tackle climate change are clarified in detail.
\end{abstract}

Keywords: Energy, GHG emissions, decomposition analysis, driving factors, LMDI Method, Turkey 


\section{Introduction}

Global warming and climate change is a worldwide issue that puts life on Earth seriously at risk. It threatens humanity's lives, destroys state economies, and transforms ecosystems. One million of the eight million species on the planet are at risk of being lost. Forest and oceans are being polluted and destroyed. The combating climate changes unavoidable damages economic growth in the long run unless measures are taken in the short term. Continued emissions of greenhouse gases would result in higher heating and long-term changes in all climatic characteristics. It would increase the probability of extreme, extensive, and inevitable effects on humans and the environment [1]. Therefore, people should immediately begin to engage in urgent, active, and cooperative actions based on mutual trust and understanding.

The energy sector is generally the most relevant in inventories of greenhouse gas emission, typically contributing more than $90 \%$ of $\mathrm{CO}_{2}$ emissions and 75 per cent of the overall greenhouse gas emissions in most countries. These values are 86.3 per cent and 72.2 per cent for Turkey in 2017, respectively. $\mathrm{CO}_{2}$ is responsible generally for $95 \%$ nitrous oxide and methane emissions of in energy sector [2]. Stationary combustion typically accounts for around 70 per cent of the energy sector GHG emissions. In the energy industries, approximately halves of those pollutants are connected to burning, especially energy plants and refineries. Mobile ignition is responsible for around one-quarter of the energy sector's emissions [3].

The Turkish economy and the nation's energy demand have steadily grown developments that are expected to continue. Turkey has an emerging private industrial economy in the fields of basic manufacturing, construction, finance, transportation, and communication. The Turkish market had a real annual gross domestic product (GDP) growth rate of 4.8\% from 1998 to 2017 . GDP increased to over USD 1.206 billion in 2017, up from USD 505 billion in 1998. With its increasing energy needs primarily met by fossil fuels -particularly coal for electricity 
generation - Turkey's emissions are expected to rise substantially. Turkey's energy mix remains carbon-intensive, with fossil fuels representing $88 \%$ of total primary energy supply (TPES). The country dependents heavily on imported energy, notably oil and natural gas. Therefore, Turkey's increase in greenhouse gas (GHG) emissions over the past decade. The overall GHG emissions were 526.3 $\mathrm{Mt} \mathrm{CO}_{2}$ eq. in 2017, excluding the land use, land-use change, and forestry (LULUCF) sector. This value represents an increase of $245.6 \mathrm{Mt} \mathrm{CO}_{2}$ eq. $(87.8 \%)$ on total emissions in 1998 [3]. The primary reasons for the rise in all sectors are population growth, a rising economy, and increased demand for energy.

Turkey's energy demand growth is among the highest in the Organization for Economic Cooperation and Development (OECD). TPES has increased by $76 \%$ since 2005 . This tendency would probably continue for the medium and long term. In 2023, the government expects primary energy demand to hit 218 million tons of oil equivalent (toe). Therefore, Turkey plans to reduce import dependency and ensure energy security by diversifying imports, integrating regional markets, increasing domestic production of coal, renewables and nuclear energy, and promoting energy efficiency.

Energy intensity (TPES divided by GDP) is around the OECD average. Turkey's energy intensity reduction goal of $20 \%$ by 2023 from 2011 requires additional efforts to be reached TPES intensity has decreased to $96 \%$ of the 2005 value. In contrast, the total final consumption intensity has decreased more as a percentage of $88 \%$. The decrease in energy intensity is, however, nor steady. It remains dependent on external economic conditions, as the effect of the 2008-2009 global economic recession [4].

Since sustainable development and combating climate change became a vital issue in the $21 \mathrm{st}$ century, Turkey's governance should concentrate on both achieving economic efficiency and should also enhance the conservation of energy and ecological safety. For this purpose, Turkey could implement a long-term low-emissions policy that incorporates climate and energy targets. 
Therefore, the primary purpose of this study is to suggest an alternative strategy to analyze the sources of changes in energy-related emissions and assess the relative contributions of the sources for reducing emissions. To achieve this purpose, we try to identify and analyze the driving factors that contribute to changes in emissions in Turkey's high energy-intensive sectors (manufacturing industries and construction, transport, commercial/institutional/residential and agriculture/forestry/fishing) from 1998 to 2017. They have been analyzed based on the Logarithmic Mean Divisia Index (LMDI) method in this study. The LMDI method developed by Ang [1] is employed to decompose the changes in these sectors' $\mathrm{CO}_{2}$ equivalent emissions into five leading forces for reach GHG emissions reduction goals and determined to achieve a low-carbon transition for Turkey. These driving factors are; changes in economic activity $\left(\Delta \mathrm{C}_{\text {act }}\right)$, structure effect $\left(\Delta \mathbf{C}_{\text {str }}\right)$, sectoral energy intensity $\left(\Delta \mathbf{C}_{\text {int }}\right)$, sectoral energy mix $\left(\Delta \mathbf{C}_{\mathbf{m i x}}\right)$, and emission factors $\left(\Delta \mathbf{C}_{\mathbf{e m f}}\right)$. Four types of fuels were used in the analyses; solid, liquid, gaseous, and other fossil fuels. Since $\mathrm{CO}_{2}$ emissions from biomass are not be included in the total $\mathrm{CO}_{2}$ emissions from fuel combustion, the biomass fuel type is not considered. GDP could be seen as the main driver of the GHG emissions in Turkey. Because GDP has increased with a ratio of $138.5 \%$, and this ratio is more significant than the rising of GHG emissions in the same period, even though there is a rising trend in total emissions from 1998 to 2017. The essential and interesting main findings are; 1) Economic activity (GDP) is the crucial decisive factor behind the change in $\mathrm{CO}_{2}$ emissions and accounts for most emissions 2) the driving factors of energy intensity, energy mix, and energy structure have a decreasing effect. There is a rising trend in the total GHG emissions from 1998 to 2017; however, the economic recession had directly caused a reduction in the total GHG emissions in 1994, 1999, 2001, and 2008.

\section{Literature review}


In this analysis, the LMDI (Logarithmic Mean Divisia Index) method developed by Ang [5] is employed among available methods to identify the key contributing factors to the increased $\mathrm{CO}_{2}$ emissions of Turkey's four foremost combustion sectors. Ang stressed that the decomposition analysis had become an increasingly important subject area in the energy field in the last 40 years. He analyzed different index decomposition analyses and proposed that the multiplicative and additive LMDI method is used in the sense of decomposition analysis because of its analytical structure, ease of usage and adjustability and interpretation of results, and some other attractive features.

The LMDI method of decomposition has become a commonly utilized technique for analyzing ecological subject matter to evaluate the factors affecting the carbon emissions of many industries. Since its incomparable advantages, including a high analytical basis and proper adjustment in the application. That's why it is used in different countries such as China [[6][15]], Greece [16], Tunisian [17], India [18], Nigeria [19], Spain [20], Mexico [21], Philippine [22] and Turkey [23]-[27]. Researchers usually tend to use five main factors for the decomposition factors; industrial activity, industrial structure, energy structure, energy intensity, and emission factor. Some of the other researchers have added three other factors, such as; productivity, investment intensity research \& development, to analyze these factors affecting GHG emissions in many industries, especially the industrial sector [28].

Gonzalez and Martinez [21] performed a decomposition study to describe the forces that affected the alteration in the greenhouse gas in entire Mexico's industry and its 16 critical industrial sub-divisions throughout the period 1965-2003. They found the impacts of activity, composition, and fuel mix for electricity generation led to increasing $\mathrm{CO}_{2}$ emissions from 1965 to 2003 , respectively, they were mitigated by energy intensity and end-use fuel mix. Zhang et al. [6], Emodi et al. [19], and Sumabat et al. [22] used the LMDI decomposition technique to analyses $\mathrm{CO}_{2}$ emissions from power production in China, Nigeria and Philippine. They noticed 
that the most crucial contribution to rising $\mathrm{CO}_{2}$ emissions from power production is the effect of economic activity. Economic activities and energy intensity are the primary but adverse effects of energy-related carbon emissions. Thus, while financial activities increase energyinduced carbon emissions, energy intensity has a decreasing effect. The Industry and its subsectors are energy-intensive sectors and hence produce significant carbon emissions. Therefore, scholars have done much scientific research on the decomposition analysis of the industry.

Akbostancı et al. [23] analyzed the greenhouse gases from Turkish manufacturing that covers 57 industries of Turkey from 1995 to 2001 by implementing the LMDI technique and identified that variations in industrial development and intensity of energy are the primary key drivers of alterations in greenhouse gases. Coal is the crucial determinant in fuels, while steel and iron industry sectors are the most polluting industry-dominating $\mathrm{CO}_{2}$ emissions in the production sector of Turkey.

Lise [24] also found that relatively rapidly growing economies, the most significant key driver in raising $\mathrm{CO}_{2}$ emissions is economic development. In contrast, the decreasing energy intensifies of the economy is accounted for a small decline in $\mathrm{CO}_{2}$ emissions in Turkey during the period 1980-2003.

Akbostanc1 et al.[25] decomposed and analyzed $\mathrm{CO}_{2}$ emissions of five sectors of the Turkish economy between 1990 and 2013. These sectors are; manufacturing, electricity and heat production, transportation, and residential industries. They found that the intensity of energy and economic activity is the decisive key drivers that cause a change in $\mathrm{CO}_{2}$ emissions. The first two sectors (MC and electricity) are the main crucial sectors that prevail in the alteration in GHG emissions. Furthermore, particularly for the MC sector, the fuel mixture component reduces the $\mathrm{CO}_{2}$ emissions during the times of economic downturn.

Tunç et al. [26] also utilized the LMDI technique to determine the decisive determinant of three main sectors of Turkey (agriculture, manufacturing, and services) carbon dioxide emissions. 
Tunç and his colleagues decomposed and analyzed GHG emissions of Turkey for 1970-2006 for examining the impacts of various macroeconomic policies on GHG emissions employing alteration in a portion of manufacturing and the usage of distinct energy resources. The investigation concluded that the primary increase in greenhouse gases is economic growth. In contrast, energy intensity brings down $\mathrm{CO}_{2}$ in 1980-1990 and 1995-2008 periods, and the industrial system is not a significant factor in minimizing carbon dioxide. Moreover, taking into account the contributions of sectors to $\mathrm{CO}_{2}$ emission changes, it was also found key drivers in $\mathrm{CO}_{2}$ emissions; the industry and services industries as predicted. The industry's contribution has increased in the latest years.

Rüstemoğlu [28] aimed to identify and analyze the factors that are increasing or decreasing the $\mathrm{CO}_{2}$ emissions for Turkey and Iran between 1990-2011 by utilizing the LMDI decomposition technique. The primary determinant of $\mathrm{CO}_{2}$ emissions for both countries is economic development and population. Surprisingly, the impact of energy intensity could be the third significant determining factor in Iranian carbon emissions. In contrast, it has a minimal lower impact on Turkey.

Ediger and Havuz [29] have used the LMDI method for evaluating sectoral energy usage in the Turkish market from 1980-2000. While there is a strong connection between primary energy usage and Gross Domestic Product, analyzes indicate that there were significant differences in the sectoral energy consumption during the periods 1982, 1988-1989, 1994, and 1998-2000. They concluded that the vital driving force for strengthening the Turkish economy's energyeconomy relationship seems to be government policies. Such policies would include improvements in the composition of final energy needs, improved material, and energy quality, and the replacement of more suitable products and oils.

Chontanawat et al. [30] also used the LMDI method to decompose the Thai manufacturing sector's source of changes in the level of $\mathrm{CO}_{2}$ emissions and the rate of $\mathrm{CO}_{2}$ emissions for the 
period 2005-2017. They found that the level of $\mathrm{CO}_{2}$ emissions and the intensity of $\mathrm{CO}_{2}$ emissions increased yearly on average during this timeframe. The effect of the systemic change led to alleviate both the sum of $\mathrm{CO}_{2}$ pollution and the emission intensity. However, the rising energy production of each enterprise increased the sum of $\mathrm{CO} 2$ emissions and the rate of $\mathrm{CO}_{2}$ emissions. The study, therefore, argues for strategies to curb the energy density of enterprises in industries to Thailand can profit through growing without having to incur pollutants furthermore.

Trotta [31] has isolated and quantified energy savings generated by improvements in energy efficiency from factors influencing the variance in Finland's final energy consumption between 2005-2015 by using a multi-sectoral LMDI-I decomposition method. Statistics show that efficiency saved 0.58 Mtoe (million tonnes of oil equivalent) of final energy from 2005 to 2015; the final energy usage in 2015 would've been 2.4 per cent higher without changes in the energy efficiency between 2005 and 2015. The savings estimated with the LMDI are substantially smaller relative to the energy consumption savings reported by the Finnish Government to the European Commission.

Shao et al. [32] have used the LMDI model. Tapio decoupling model and an emission estimation technique to predict to analyze the related decoupling and its impact influence the growth of China's commercial aviation and pollution, along with estimate predicted $\mathrm{CO}_{2}$ pollution. They found that cumulative greenhouse gases change over time on a generally ascending tendency, but there is consistent downward tendency oil consumption per tonnekilometer revenue. The transportation quantities growth impact is contributing effect to increased $\mathrm{CO}_{2}$ pollution among the four main drivers; accompanied by changes in the transport structure and alternate fuel effects. The "pace of energy consumption" aspect plays an essential part in hindering $\mathrm{CO}_{2}$ emissions. They also ended up estimating that China's commercial 
aviation would be accountable for $0.13 \mathrm{Gt}$ of $\mathrm{CO}_{2}$ emissions by 2020 depending on eight simulations. A factor of 1.6 to 3.9 could raise $\mathrm{CO}_{2}$ emissions between 2020 and 2050 .

Shao et al. [33] have used LMDI to factors influencing the usage of natural gas in every province in China. Generally, the primary critical factors of natural gas usage are the financial impact and the impact of the fossil fuel energy sector. The analyzes show that the effect on energy intensity is one of the critical restricting drivers for natural gas consumption; the most significant key drivers for natural gas usage in the net spillover block is the economic impact, followed by spatial expansion. They also found that low energy performance is a significant impediment to the growth of the Xinjiang and Ningxia natural gas sectors. The effect of population density is a significant driver leading to a discrepancy between Beijing and Shanghai in the market competition for natural gas. They concluded that it is particularly significant to prepare reasons for the growth of the natural gas sector to attain the energy transition targets and propose that the Chinese government increasing tax transfer payments, help net spillover growth.

Zhang et al. [34] analyze the decoupling elasticity in China and the ASEAN nations regarding carbon dioxide, national income (GDP), and energy usage during the time 1990-2014. Based on the LMDI, it discusses the influence of four drivers on overall $\mathrm{CO}_{2}$ emission increases, namely the effect of carbon density, the effect of energy intensity, the GDP per capita, and the economic impact of the population. The study reveals that the effect of GDP per capita is the primary factor behind increased $\mathrm{CO}_{2}$ emissions. The carbon concentration and the impact of the population also play a role here. The intensity of carbon has strongly significantly contributed to the decline in $\mathrm{CO}_{2}$ emissions in almost all the nations studied. In $\mathrm{C}$, carbon policies were aimed to decomposition financial development from ecological pressure. Energy policies need to increase the proportion of renewable energy sources in China and the ASEAN 
nations, raising energy efficiency, and introduce ecological growth as lengthy-term goals in the countries to decouple financial development from ecological repression.

Zhang et al. [35] have utilized the LMDI framework relying on a fundamental economic and tech-theoretical approach to disintegrate alterations in the carbon density of the Chinese manufacturing sectors into three growth factors (potential carbon intensity, potential energy output, and industrial energy carbon output), three development-related factors (ER, Effects of energy usage ratio to research and development, and expenditure size, as well as one common factor (IS). The key drivers illustrated various effects on different manufacturing categories (or subsectors) and rates due to the variations in the industrialization stage, growth type, manufacturing investment, and research and development spending. Thus this analysis both discussed the general level of the manufacturing industry and explored the key drivers in each stage of economic development from the perspectives of the market segment and industry category.

Wang et al. [36] used the aggregate strength of the production of nitrogen oxides (ANI) to be temporarily and spatially decomposed from an electricity-related NOx processing context. In China, ANI decreased substantially between $2.90 \mathrm{~g}$ NOX / kilowatt hour to $2.15 \mathrm{~g}$ NOX / kilowatt-hour at the country level from 2000 to 2016. Their functional and geographic decomposition findings indicate that the key factors were renewable energy infiltration and thermal power generating productivity, which lowered ANI by $10.5 \%$ and $7.74 \%$ throughout the study time comparatively. Furthermore, the main contributors to ANI reduction were the ups in the southwestern, southern, and northwestern areas. $\mathrm{U}_{\text {int }}$ in the East region was the main contributor to rising ANI. Multiple $\mathrm{NO}_{\mathrm{X}}$ emission control approaches are formulated for various provinces based on the results. Thus these policies would enhance efforts to reduce source $\mathrm{NOX}$ emissions. 
Qian et al. [37] examined the related decoupling between Chinese industrial $\mathrm{SO}_{2}$ emissions from 1996-2015 and the industrial economy. Instead, the LMDI decomposition approach is utilized to evaluate the key drivers behind industrial $\mathrm{SO}_{2}$ pollution. The research phase is categorized through four phases, depending on the decoupling results: 1996-2001, 2001-2006, 2006-2010, and 2010-2015. They have found that $\mathrm{SO}_{2}$ generation strength and $\mathrm{SO}_{2}$ reduction are the key drivers to the reduction of manufacturing $\mathrm{SO}_{2}$ emissions while the primary inhibitory factor is the effect of economic activity. Besides, in some of these areas, the economic structure and the strength of the $\mathrm{SO}_{2}$ generation indicate negative contributions to rising industrial $\mathrm{SO}_{2}$ emissions.

Song et al. [38] examined the decoupling state and reduction capacity of emissions from the transportation industry throughout the 1991-2015 period. Their study uses the technique of LMDI to classify influential drivers that control emissions of this sector in China. While economic development drivers have raised the emissions, the $\mathrm{CO}_{2}$ coefficient impact has decreased emissions. Over the period 1991-2015, extensive coupling (EC) with economic development posed $\mathrm{CO}_{2}$ emissions from China's transportation sector.

Fang et al. [39] used the ST-LMDI multi-period model by establishing a single baseline region as a standard for various regions in China to decompose the variations in electricity consumption of China fully. Economic development has been found to have a substantial impact on energy consumption, while technological development can efficiently mitigate it. Furthermore, the outcomes of analyzing electricity usage from an industrial and regional context demonstrate that the economic system and intensity of usage have different effects in the eastern, central, and western regions.

Li et al.[40] examined the spatial pattern progression of transport emissions in China from 2005 to 2015, after analyzing the emissions from transport in China's 341 regions. Depending on index decomposition evaluation, GDP per capita and population increases were the most 
significant factors affecting emission rising, respectively. Transportation carbon emissions per GDP was, however, a determinant of emissions reductions.

Jiang et al. [41] used a Kaya identity-based method of the LMDI to decompose the determining drivers via growth of population, economic development, regional trade system, regional industry system, and energy usage. They have studied the non-residential energy consumption of China from 2007 to 2016. They consider that economic development is the key factor affecting the increasing energy consumption in non-residential areas. Besides, the increased energy consumption rate as a second key factor reduces the growth of non-residential electricity usage. Finally, growth in the population as the third factor has a low impact on rising electricity usage.

Jiang et al. [42] used a multi-regional input-output method to measure the energy consumption embedded in the global trade of 39 nations from 1995 to 2011. Later, they used the LMDI method to describe the main factors of energy consumption. They found that foreign trade development, economic growth, and inhabitants are due to increased use of embodied energy. Conversely, the modernization and optimization of industrial systems and structures would support to reduce the growth of embodied energy usage.

To achieve emission reduction targets for determining to make a low-carbon transition of Turkey, we conduct a specific investigation on Turkish high-energy intensive combustion four sectors: manufacturing industries and construction sector (MC), transport sector, commercial/institutional/residential sector (CIM), and agriculture/forestry/fishing sector (AFF) for period 1998-2017 by employing LMDI-I method.

\section{Methodology and data source}




\subsection{The LMDI method}

The LMDI method developed by Ang [5] is used in this study to decompose the driving factors of on Turkish main four combustion sectors $\mathrm{CO}_{2}$ emissions from four fuel type combustion as follows:

$C=\sum_{i j} C_{i j}=\sum_{i j} Q \frac{Q_{i}}{Q} \frac{E_{i}}{Q_{i}} \frac{E_{i j}}{E_{i}} \frac{C_{i j}}{E_{i j}}=\sum_{i j} Q S_{i} I_{i} M_{i j} U_{i j}$

Where $\mathrm{C}$ is the total $\mathrm{CO}_{2}$ emissions of Turkish four combustion sectors; i specifies the $\mathrm{i}$-th combustion sector; $\mathrm{j}$ represents the $\mathrm{jth}$ type of fuel; $\mathrm{C}_{\mathrm{ij}}$ is the $\mathrm{CO}_{2}$ emissions from fuel $\mathrm{j}$ in the sector $\mathrm{i}, \mathrm{Q}\left(=\sum \mathrm{Q}_{\mathrm{i}}\right)$ is the overall economic activity level, $\mathrm{Q}_{\mathrm{i}}$ is the activity level of sector $\mathrm{i}$, $E_{i}\left(=\sum E_{i j}\right)$ is the $j$ type of energy usage of sector $i$, and the unit of this variable is $T j, E_{i j}$ is the consumption of fuel $\mathrm{j}$ in sector $\mathrm{i}$. The unit of $\mathrm{CO}_{2}$ emissions is $10^{3}$ tons, and energy consumed is taken as $10^{9}$ kilojoules.

Where $\mathrm{S}_{\mathrm{i}}=\mathrm{Q}_{\mathrm{i}} / \mathrm{Q}$ represents the industrial structure, $\mathrm{I}_{\mathrm{i}}\left(=\mathrm{E}_{\mathrm{i}} / \mathrm{Q}_{\mathrm{i}}\right)$ represents the energy intensity of sector $\mathrm{i} ; \mathrm{M}_{\mathrm{ij}}\left(=\mathrm{E}_{\mathrm{ij}} / \mathrm{E}_{\mathrm{i}}\right)$ is the fuel-mix variable, and $\mathrm{U}_{\mathrm{ij}}\left(=\mathrm{C}_{\mathrm{ij}} / \mathrm{E}_{\mathrm{ij}}\right)$ represents the $\mathrm{CO}_{2}$ emissions factor of fuel $\mathrm{j}$ consumed in i sector.

The general identity of decomposition index is given by

$V=\sum_{i} V_{i}=\sum_{i} x_{1, i} x_{2, i} \ldots \ldots . x_{n, i}$

The aggregate changes from $\mathrm{V}^{0}=\sum_{i} x^{0}{ }_{1, i} x^{0}{ }_{2, i} \ldots \ldots x^{0}{ }_{n, i}$ in period 0 to $\mathrm{V}^{\mathrm{T}}=\sum_{i} x^{T}{ }_{1, i} x^{T}{ }_{2, i} \ldots x^{T}{ }_{n, i}$ in period $\mathrm{T}$,

In multiplicative decomposition, we decompose the ratio:

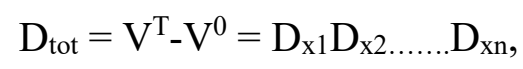

In additive decomposition, we decompose the difference: 
$\Delta \mathrm{V}_{\text {tot }}=\mathrm{V}^{\mathrm{T}}-\mathrm{V}^{0}=\Delta \mathrm{V}_{\mathrm{x} 1}+\Delta \mathrm{V}_{\mathrm{x} 2}+\ldots . .+\Delta \mathrm{V}_{\mathrm{xn}}$

where subscription of tot indicates overall or sum change and the superscript $\mathrm{T}$ refers to period $\mathrm{T}$ and 0 refers to period 0 .

The basic equations for the impact of the kth component on the right side of Equations (3) and

(4) are alternatively used in the LMDI approach:

$D_{x_{k}}=\exp \left(\sum_{i} \frac{L\left(V_{i}^{T}, V_{i}^{0}\right)}{L\left(V^{T}, V^{0}\right)} \ln \left(\frac{x_{k, i}^{T}}{x_{k, i}^{0}}\right)\right)$

$=\exp \left(\sum_{i} \frac{\left(V_{i}^{T}-V_{i}^{0}\right) /\left(\ln V_{i}^{T}-\ln V_{i}^{0}\right)}{\left(V^{T}-V^{0}\right) /\left(\ln V^{T}-\ln V^{0}\right)} \ln \left(\frac{x_{k, i}^{T}}{x_{k, i}^{0}}\right)\right)$

$$
\begin{aligned}
\Delta \mathrm{V}_{x_{k}} & =\sum_{i} L\left(V_{i}^{T}, V_{i}^{0}\right) \ln \left(\frac{x_{k, i}^{T}}{x_{k, i}^{0}}\right) \\
& =\sum_{i} \frac{V_{i}^{T}-V_{i}^{0}}{\ln \left(V_{i}^{T}-V_{i}^{0}\right)} \ln \left(\frac{x_{k, i}^{T}}{x_{k, i}^{0}}\right)
\end{aligned}
$$

Where $\mathrm{L}(\mathrm{a}, \mathrm{b})=(\mathrm{a}-\mathrm{b}) /(\ln \mathrm{a}-\ln \mathrm{b})$, where both $\mathrm{a}$ and $\mathrm{b}$ positive numbers and $\mathrm{a}=\mathrm{b}$ as defined in Ang, 2004 [43] . Therefore, the changes in the $\mathrm{CO}_{2}$ equivalent emissions of four incineration sectors in Turkey between a target year $\mathrm{t}$ and a base year 0 , displayed by $\Delta \mathrm{C}_{\text {tot }}$ has been decomposed by the LMDI into the five components as illustrated;

(i) the economic activity effect (shown as $\Delta \mathrm{C}_{\text {act }}$ );

(ii) the structure effect (shown as $\Delta \mathrm{C}_{\text {str }}$ );

(iii) the sectoral energy intensity effect (shown as $\Delta \mathrm{C}_{\mathrm{int}}$ );

(iv) the sectoral energy-mix effect (shown as $\Delta \mathrm{C}_{\text {mix }}$ ); and

(v) the emissions factor effect (denoted as $\Delta \mathrm{C}_{\mathrm{emf}}$ ) in additive form,

as shown in Equation (6): 
$\Delta \mathrm{C}_{\mathrm{tot}}=C^{T}-C^{0}=\Delta \mathrm{C}_{\mathrm{act}}+\Delta \mathrm{C}_{\mathrm{str}}+\Delta \mathrm{C}_{\mathrm{int}}+\Delta \mathrm{C}_{\mathrm{mix}}+\Delta \mathrm{C}_{\mathrm{emf}}$

The LMDI can be expressed as:

$$
\begin{aligned}
\Delta \mathrm{C}_{\mathrm{act}} & =\sum_{\mathrm{ij}} \frac{\mathrm{C}_{\mathrm{ij}}^{\mathrm{T}}-\mathrm{C}_{\mathrm{ij}}^{0}}{\ln \mathrm{C}_{\mathrm{ij}}^{\mathrm{T}}-\ln \mathrm{C}_{\mathrm{ij}}^{0}} \ln \left(\frac{\mathrm{Q}^{\mathrm{T}}}{\mathrm{Q}^{0}}\right) \\
\Delta \mathrm{C}_{\mathrm{str}} & =\sum_{\mathrm{ij}} \frac{\mathrm{C}_{\mathrm{ij}}^{\mathrm{T}}-\mathrm{C}_{\mathrm{ij}}^{0}}{\ln \mathrm{C}_{\mathrm{ij}}^{\mathrm{T}}-\ln \mathrm{C}_{\mathrm{ij}}^{0}} \ln \left(\frac{\mathrm{S}_{i}^{\mathrm{T}}}{\mathrm{S}_{i}{ }^{0}}\right) \\
\Delta \mathrm{C}_{\mathrm{int}} & =\sum_{\mathrm{ij}} \frac{\mathrm{C}_{\mathrm{ij}}^{\mathrm{T}}-\mathrm{C}_{\mathrm{ij}}^{0}}{\ln \mathrm{C}_{\mathrm{ij}}^{\mathrm{T}}-\ln \mathrm{C}_{\mathrm{ij}}^{0}} \ln \left(\frac{\mathrm{I}_{i}^{\mathrm{T}}}{\mathrm{I}_{i}{ }^{0}}\right) \\
\Delta \mathrm{C}_{\mathrm{mix}} & =\sum_{\mathrm{ij}} \frac{\mathrm{C}_{\mathrm{ij}}^{\mathrm{T}}-\mathrm{C}_{\mathrm{ij}}^{0}}{\ln \mathrm{C}_{\mathrm{ij}}^{\mathrm{T}}-\ln _{\mathrm{ij}}^{0}} \ln \left(\frac{\mathrm{M}_{i j}{ }^{\mathrm{T}}}{\mathrm{M}_{i j}{ }^{0}}\right) \\
\Delta \mathrm{C}_{\mathrm{emf}} & =\sum_{\mathrm{ij}} \frac{\mathrm{C}_{\mathrm{ij}}^{\mathrm{T}}-\mathrm{C}_{\mathrm{ij}}^{0}}{\ln \mathrm{C}_{\mathrm{ij}}^{\mathrm{T}}-\ln _{\mathrm{ij}}^{0}} \ln \left(\frac{\mathrm{U}_{i j}{ }^{\mathrm{T}}}{\mathrm{U}_{i j}{ }^{0}}\right)
\end{aligned}
$$

\subsection{Data Source}

The LMDI-based method of decomposition is used to determine the key drivers and to evaluate the contribution of these factors to change GHG emissions in Turkey's four-combustion sectors individually from 1998 through 2017 years. During the application of the decomposition analysis, $\mathrm{CO}_{2}$ equilibrium emissions data sets employed in the Turkish Greenhouse Gas Inventory 1990-2017 report and CRF tables submitted to the UNFCCC secretariat [3]. Therefore, the study's data set complies with international standards.

The Ministry of Treasury and Finance employs GDP and economic development data. National income statistics are obtained from the Ministry of Treasury and Finance and World Bank indicators and provided in four-sector detail; manufacturing industries and construction (MC), commercial/institutional/residential (CIR), transport, and agriculture/forestry/fishing (AFF). Even there exist disaggregated national income statistics for subsectors of manufacturing 
industries; we had to apply to aggregated data of two sectors (manufacturing industry and construction) to ensure consistency between the national income statistics and emission values, which are aggregated in CRF tables as one sector named of manufacturing industries and construction. $\mathrm{CO}_{2}$ equivalences emissions for the period of 1998-2017 are estimated by the usage of the Intergovernmental Panel on Climate Change (IPCC) manual [44]. According to the manual, $\mathrm{CO}_{2}$ equivalences can be found by the sum of $\mathrm{CO}_{2}$ emission, $\mathrm{CH}_{4}$ multiply by 25 , and $\mathrm{N}_{2} \mathrm{O}$ multiply by 298 . Four types of fuels were analyzed: solid fuels, liquid fuels, gaseous fuels, and other fossil fuels. Because in IPCC calculations $\mathrm{CO} 2$ emissions from biomass are not included in the overall $\mathrm{CO} 2$ emissions from fuel combustion, the form of biomass fuel is not taken into account.

Energy balance tables of the Ministry of Energy and Natural Resources were used for the Energy-related statistics for the period 1998-2017. In the balance sheet, there is only solid fuels, liquid fuels, gas fuels related to energy consumption values have been regarded. Renewable energy resources values are not considered since they are not emission sources. The fuel $\mathrm{j}$ consumption in sector i values $\left(E_{i j}\right)$ is collected from the CRF tables in the consumption section as TJ.

The fuel consumption of commercial/institutional is not separated in the energy balance tables until 2015; it is given under the residential sector for the 1990-2014 period. Emissions are offered under this category in 2015 for the first time, and they are included under residential for 1990-2014 periods [3]. Therefore, the aggregated values of the two sectors are used.

\section{Overview of necessary information related to the four sectors}

For most countries, energy systems are powered primarily by the combustion of fossil fuel. Generally, the energy sector is the most significant in GHG inventories, and usually generating more than $90 \%$ of the $\mathrm{CO}_{2}$ emissions and $75 \%$ of overall GHG emissions in developed 
countries. These values are 86.3 per cent and 81 per cent for Turkey's overall GHG emissions in 2017, respectively. Usually, $\mathrm{CO}_{2}$ is responsible for $95 \%$ of the nitrous oxide and methane emissions in the energy sector. Stationary combustion typically accounts for around 70 per cent of the energy sector's emissions. Around halves of those emissions are mainly related to combustion in power plants and refineries in the energy industries. Mobile combustion (road and other traffic) responsible for approximately one-quarter of energy emissions [44].

4.1. The economic activity of Turkey

The Turkish economy has $4.8 \%$ a real yearly gross domestic product (GDP) rate of growth from 1998 to 2017. In 2017, GDP increased to over \$ 1.206 billion, up from \$ 505 billion in 1998 . GDP per capita in the last decade has almost doubled in 2017 to $\$ 10.616$, up from $\$ 4.442$ in 1998. Increased greenhouse gas (GHG) emissions from Turkey over the past decade, powered by strong economic and population growth, increasing income levels, and continued dependence on carbon-intensive fuel mix, Turkey's increase in [3]. Total GHG emissions, excluding the LULUCF sector, were 526.3 $\mathrm{Mt} \mathrm{CO}_{2}$ eq. GHG in 2017. This value represents an increase of $245.6 \mathrm{Mt} \mathrm{GHG}$, with a ratio of $87.8 \%$ on total emissions in 1998 . The population growth, the economic expansion, and hence the increase in energy demand are the fundamental causes of the rise in all sectors. [3]. GDP could be seen as the main driver of the GHG emissions in Turkey. Because GDP has increased with a ratio of $138.5 \%$, and this ratio is more significant than the rising of GHG emissions in the same period. Even though there is a rising trend in the total emissions between from 1998 to 2017, the economic recession in 1999, 2001, and 2009 caused $3.4 \%, 6.0 \%, 4.7 \%$ decrease in GDP and it had directly caused a reduction in the total GHG emissions in 1999, 2001 and 2008. In these years, total emissions are decreased by $2.5 \%$, $0.9 \%, 6.2 \%$, and $1.0 \%$ as compared to the previous year's emissions, respectively. The fluctuations in the emission trends are mainly due to the directions in the economic activities, which can be seen through Gross Domestic Product (GDP) at market prices (constant 2010 
USD), as shown in Figure 1. Although there is no economic recession, total emissions were slightly decreased by $1.8 \%$ in 2013 . This finding mainly results in a change in the share of solid fuels for electricity generation.

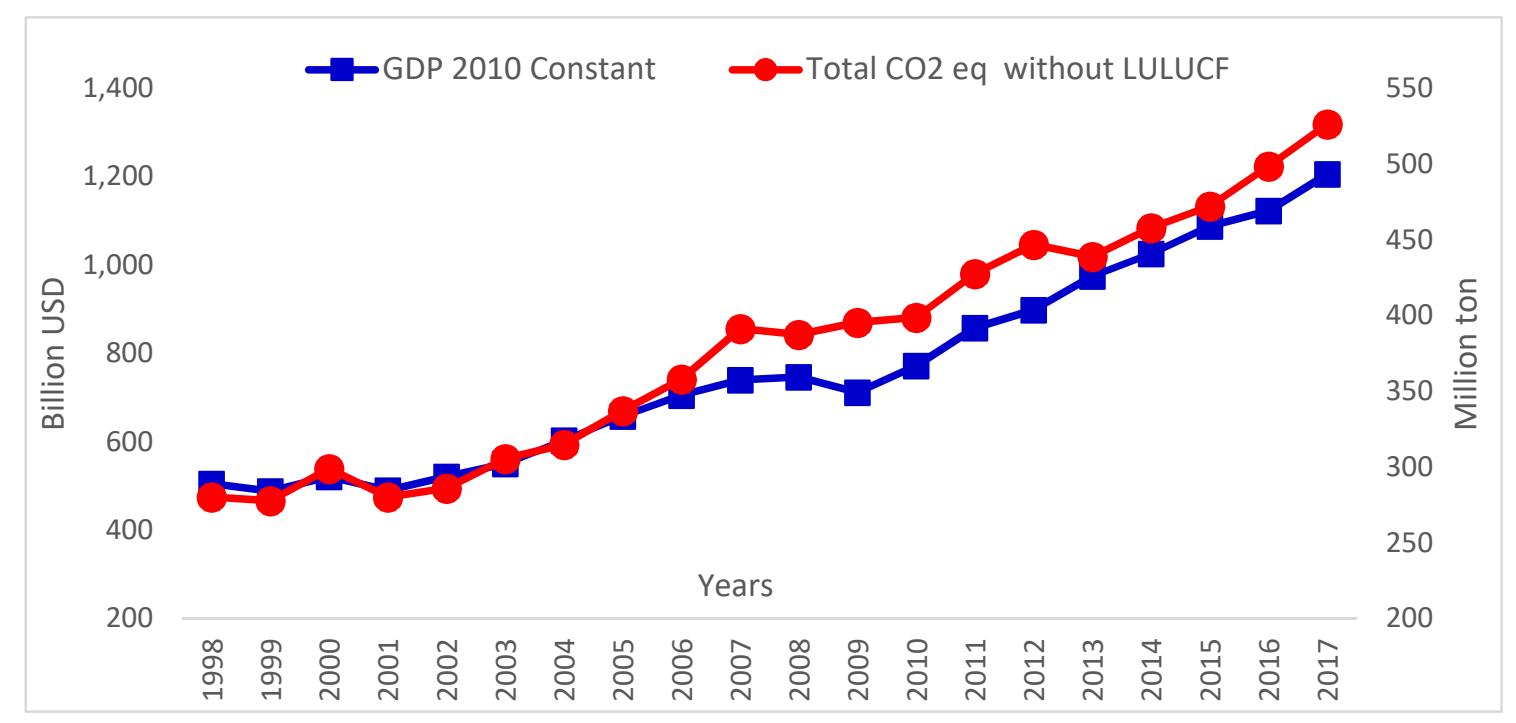

Figure 1. Total emissions and GDP trend, 1998-2017

Figure 2 indicates the sectoral portion of overall economic activity. The industrial sector had a 25-30\% proportion of GDP. At 92 per cent of the workforce, the manufacturing industry had the most substantial proportion and $82 \%$ share of turnover in the entire industrial sector [45].

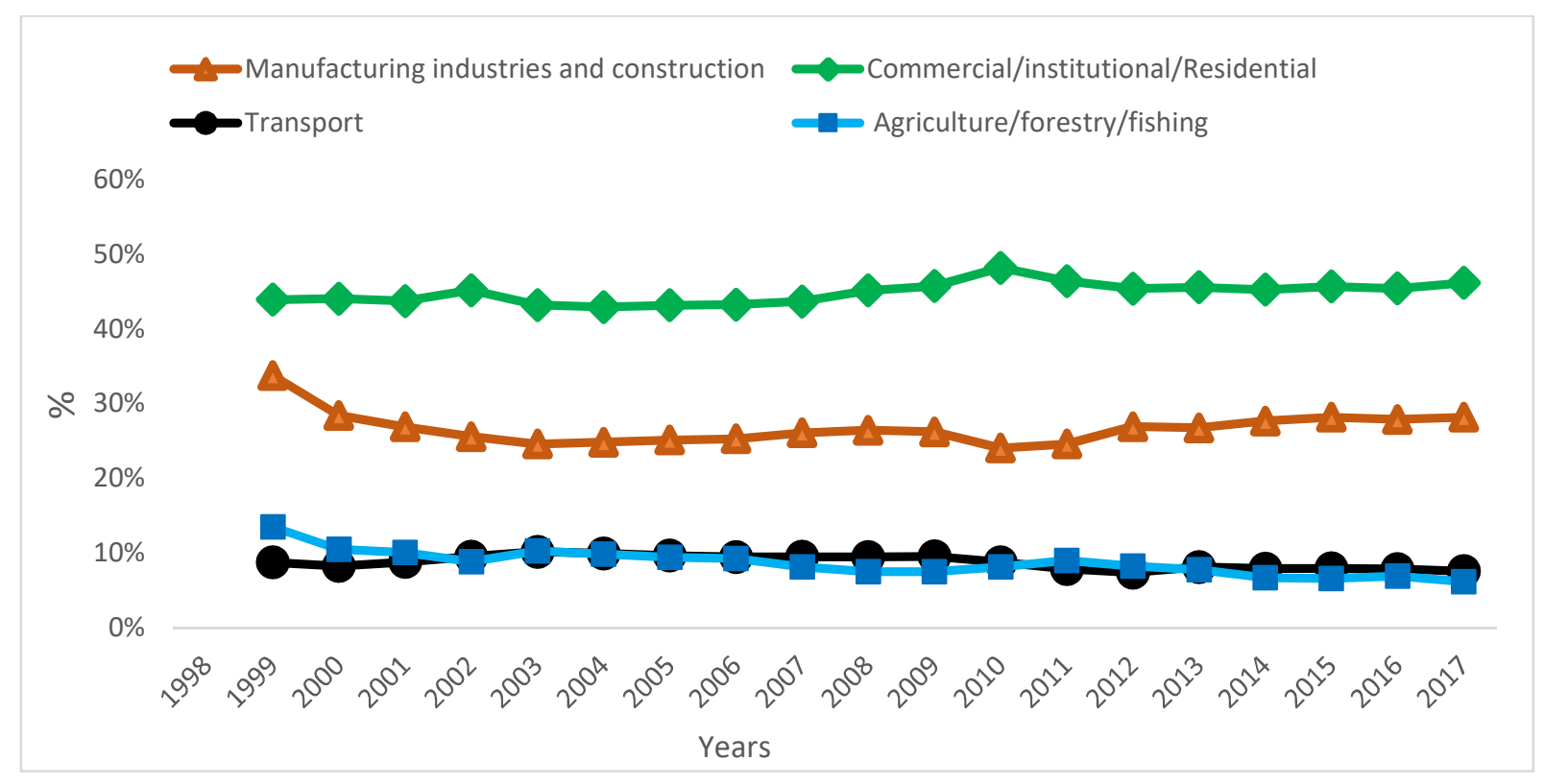

Figure 2. The proportion of sectors in an economic activity 


\subsection{Sectoral $\mathrm{CO}_{2}$ emissions in Turkey}

Among all sectors, the energy sector has the highest share, with $72.2 \%$. The total amount of the energy sector's emissions in 2017 was predicted to be $379.9 \mathrm{Mt}^{\mathrm{CO}_{2}}$ equivalent, where the industrial processes and product use is the second-largest GHG sector with $12.6 \%$. The agricultural activities with $11.9 \%$ and the waste with $3.3 \%$ follow it. $\mathrm{CO}_{2}$ emissions per capita were 4.5 tons in 1998, compared to 6.6 tons in 2017 [2]. Emissions per capita are still below the OECD average but are rising rapidly. Emissions intensity is declining, but not as much as the OECD average [4].

Table 1 shows that the combined sectoral GHG emissions of four sectors rose from $125.96 \mathrm{Mt}$ in 1998 to $218.23 \mathrm{Mt}$ in 2017. The increase rate in GHG is $73.3 \%$. The contribution of sectors to increase in GHG is $5.0 \%$ of the manufacturing sector, $38.5 \%$ of the commercial sector, 55.2 $\%$ of the transport sector, and $1.4 \%$ of agriculture sectors.

Table 1. Energy sector GHG emissions, kt $\mathrm{CO}_{2}$ eq. (1998-2017)

\begin{tabular}{|c|c|c|c|c|c|c|c|}
\hline \multicolumn{7}{|c|}{ FUEL COMBUSTION } \\
\hline Year & $\begin{array}{c}\text { Total } \\
\text { Energy }\end{array}$ & $\begin{array}{c}\text { Fuel } \\
\text { combustion } \\
\text { total }\end{array}$ & $\begin{array}{c}\text { Energy } \\
\text { industries }\end{array}$ & $\begin{array}{c}\text { Sectors } \\
\text { Total }\end{array}$ & $\begin{array}{c}\text { Manufacturing } \\
\text { industries and } \\
\text { construction }\end{array}$ & Transport & $\begin{array}{c}\text { Other } \\
\text { sectors }\end{array}$ \\
\hline 1998 & 195864 & 191119 & 65164 & 125956 & 55470 & 32782 & 37704 \\
\hline 1999 & 193817 & 188096 & 70360 & 117735 & 47365 & 34617 & 35753 \\
\hline 2000 & 216054 & 209908 & 77743 & 132165 & 57936 & 36465 & 37764 \\
\hline 2001 & 199233 & 193530 & 80022 & 113508 & 45656 & 36455 & 31397 \\
\hline 2002 & 205832 & 200415 & 74138 & 126276 & 57112 & 36234 & 32930 \\
\hline 2003 & 220300 & 215110 & 74371 & 140739 & 66682 & 37825 & 36232 \\
\hline 2004 & 226139 & 221005 & 75539 & 145466 & 63857 & 42048 & 39561 \\
\hline 2005 & 243965 & 238213 & 90458 & 147754 & 63004 & 42041 & 42709 \\
\hline 2006 & 259959 & 253874 & 96129 & 157744 & 70084 & 45424 & 42236 \\
\hline 2007 & 290771 & 282821 & 113570 & 169252 & 71874 & 52099 & 45279 \\
\hline 2008 & 287279 & 278869 & 118939 & 159930 & 47354 & 48166 & 64410 \\
\hline 2009 & 292501 & 284372 & 119280 & 165092 & 46226 & 47907 & 70959 \\
\hline
\end{tabular}




\begin{tabular}{|l|l|l|l|l|l|l|l|}
\hline 2010 & 287047 & 278821 & 113324 & 165497 & 52332 & 45392 & 67773 \\
\hline 2011 & 308666 & 299601 & 124975 & 174627 & 52585 & 47386 & 74656 \\
\hline 2012 & 320489 & 311108 & 125944 & 185163 & 61052 & 62525 & 61586 \\
\hline 2013 & 307523 & 299000 & 120773 & 178227 & 52978 & 68865 & 56384 \\
\hline 2014 & 325767 & 315551 & 131474 & 184076 & 54438 & 73559 & 56079 \\
\hline 2015 & 340907 & 335411 & 134702 & 200710 & 59585 & 75798 & 65327 \\
\hline 2016 & 359671 & 351075 & 143963 & 207113 & 60071 & 81841 & 65201 \\
\hline 2017 & 379901 & 373202 & 154971 & 218230 & 60180 & 84659 & 73391 \\
\hline
\end{tabular}

The primary source of Turkish anthropogenic greenhouse gas emissions is the energy sector. It had the highest share with $72.2 \%$ in 2017 GHG emissions (not including LULUCF). Energy sector emissions in 2017 were measured at $380 \mathrm{Mt} \mathrm{GHG}$, which $373.2 \mathrm{Mt} \mathrm{CO}_{2}$ eq. GHG is related to fuel combustion with a share of $98.2 \%$. Energy industry subsectors were the main contributor, accounting for $155.0 \mathrm{Mt} \mathrm{CO}_{2}$ eq. (40.8\%) emissions. It is followed by transport sector with 84.7 Mt (22.3\%), other sectors with 73.4 Mt (19.3\%) (Commercial / institutional / Residential with 60.2 Mt (16.6\%) and Agriculture/forestry/fishing with $10.2 \mathrm{Mt}(2.7 \%)$ and manufacturing industries and construction subsector with $60.2 \mathrm{Mt} \mathrm{CO}_{2}$ eq. GHG (15.8\%) in the same year, as shown in Figure 3 also holds for Figure 4 [3].

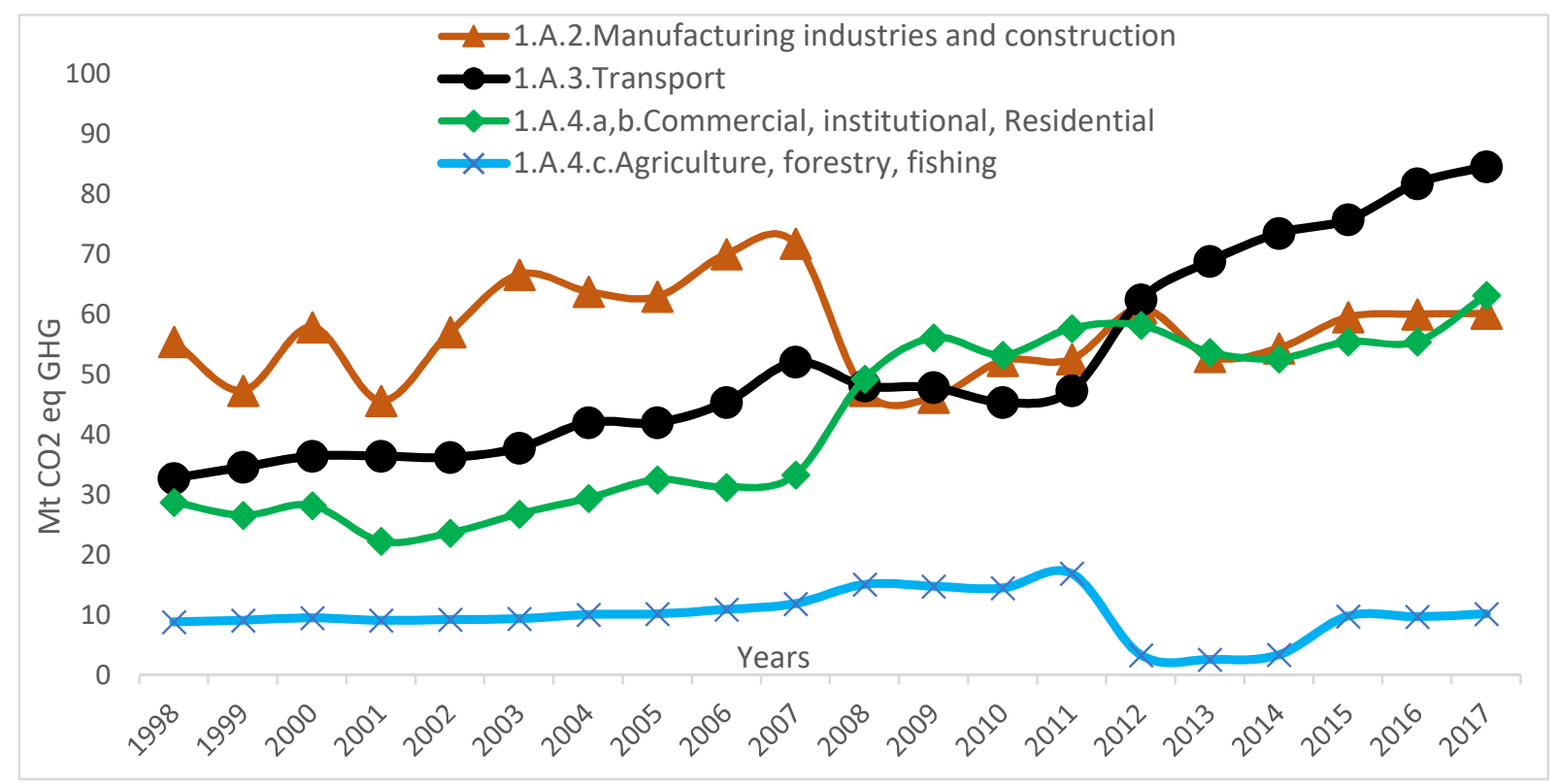

Figure 3. Energy-related $\mathrm{CO}_{2}$ equivalent emissions by sector, 1998-2017 


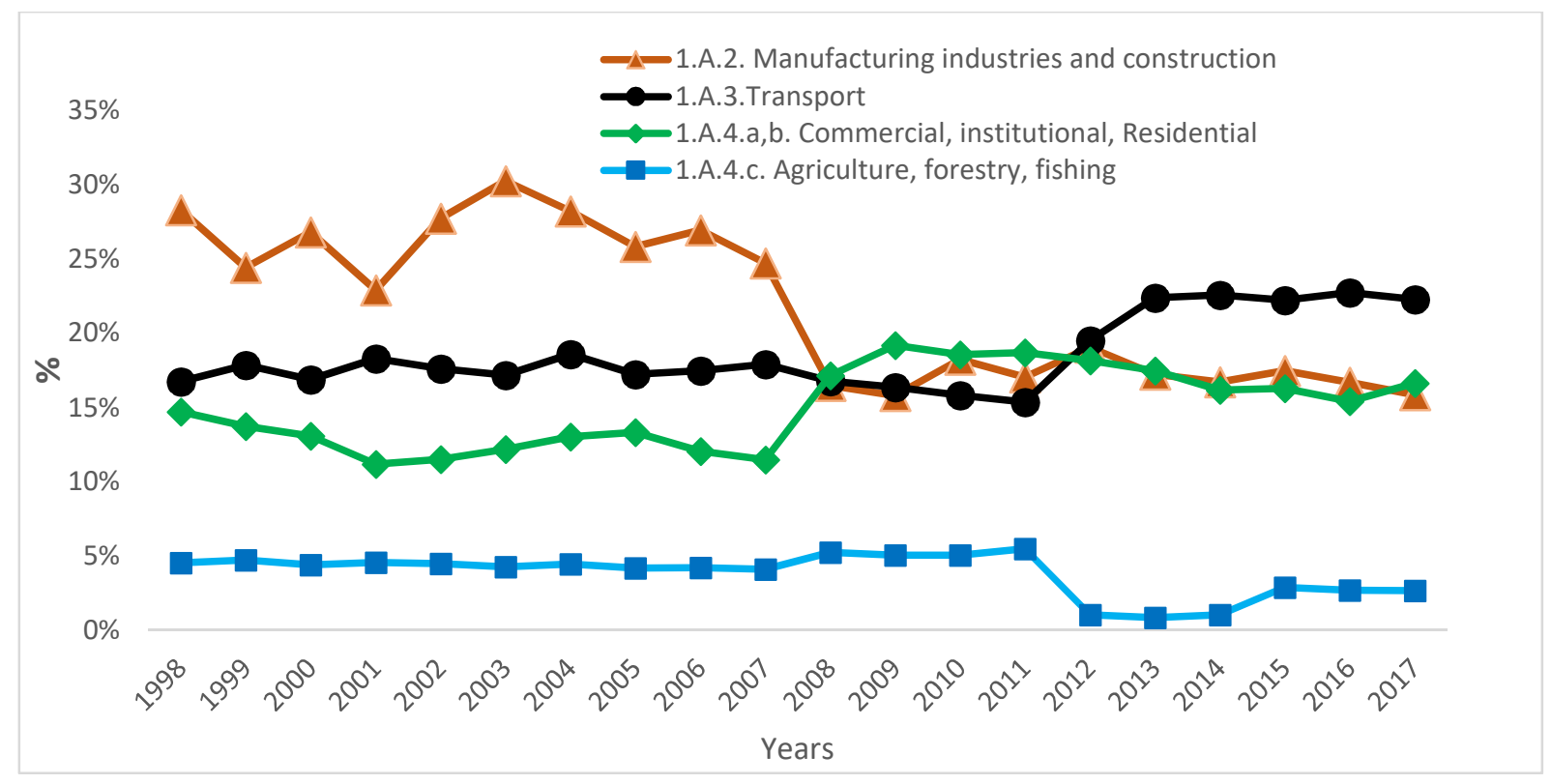

Figure 4. The shares of energy-related sectors' emissions in Turkey, 1998 to 2017

Compared to 1998 , the energy sector's total emissions were increased by $93.96 \%$. The sharpest increase in GHG emissions occurred in transportation (by 158.2\%), and Commercial Institutional, Residential services (by 119.4\%). The emissions from Agriculture, forestry, fishing, and manufacturing industries and construction sector just increased by $14.4 \%$ and $8.5 \%$, respectively, as shown in Figure 5.

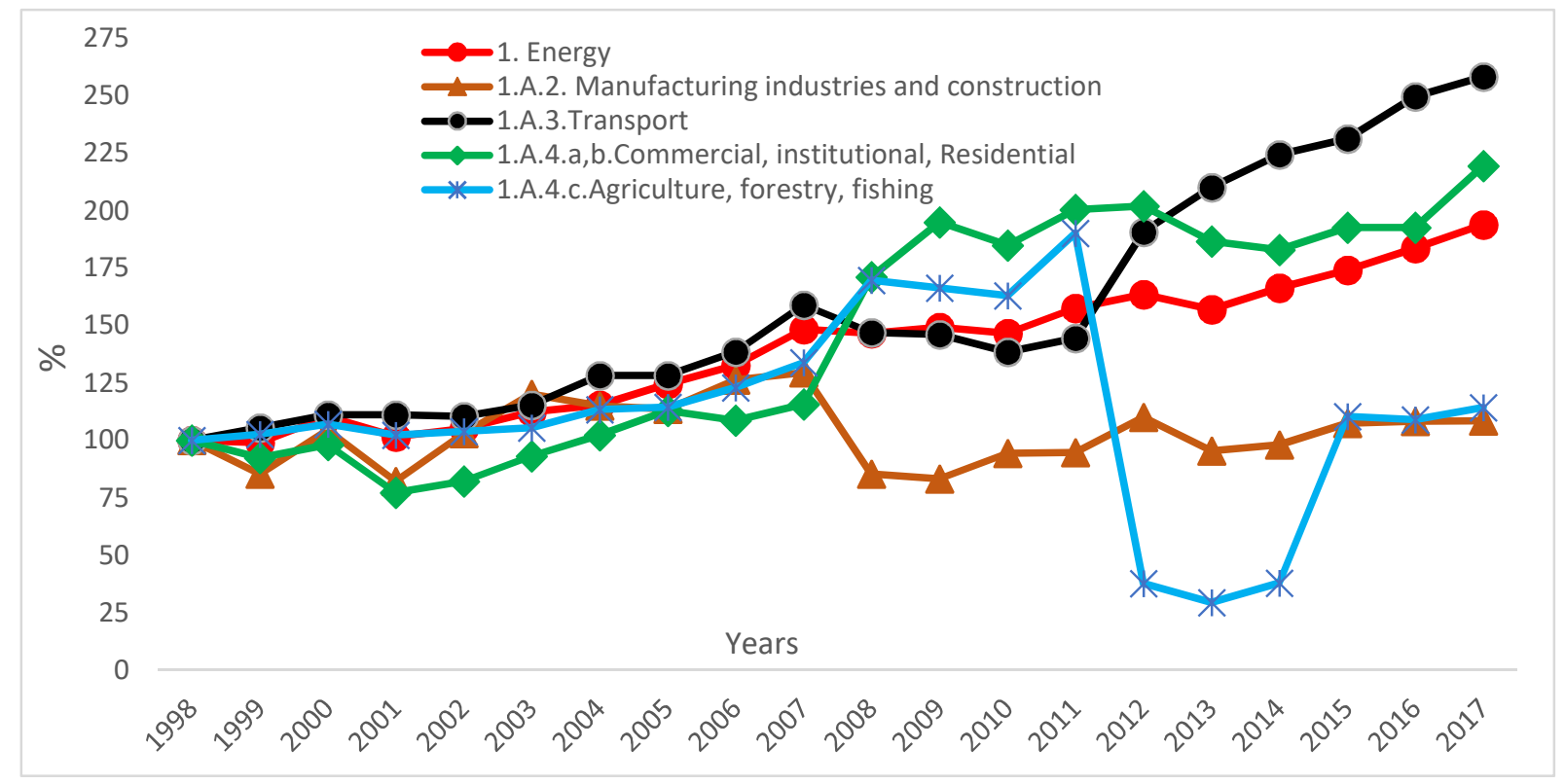

Figure 5. The rise of shares of energy-related sectors' emissions in Turkey, 1998 to 2017 


\subsection{Primary Energy use of Turkey}

Turkey's total primary energy supply had to occur as 73.3 Mtoe in 1998 , and this has been a severe increase in value 145.3 Mtoe in 2017. In total primary energy supply, the proportion of fossil fuels was $88.1 \%$, and the proportion of renewables was $11.9 \%$ in 2017 . Turkey's final energy consumption had risen from 57.1 Mtoe in 1998 to 111.7 Mtoe in 2017. The total energy consumption of four main sectors is 104.0 Mtoe, while sectors total is 111.4 Mtoe with nonenergy use part (7.4 Mtoe) [46]. Industrial and building sectors are the leading energy-intensive sectors. Manufacturing, industrial, and construction sector accounted for $31.6 \%$, commercial, institutional, and residential sector $32.3 \%$, transportation $25.5 \%$, and agriculture, forestry, and fishing $3.8 \%$ of Turkey's final energy consumption in 2017 . These values were $35.3 \%, 33.3 \%$, $18.8 \%$, and $4.9 \%$ in 1998, respectively, as shown in Figure 6.

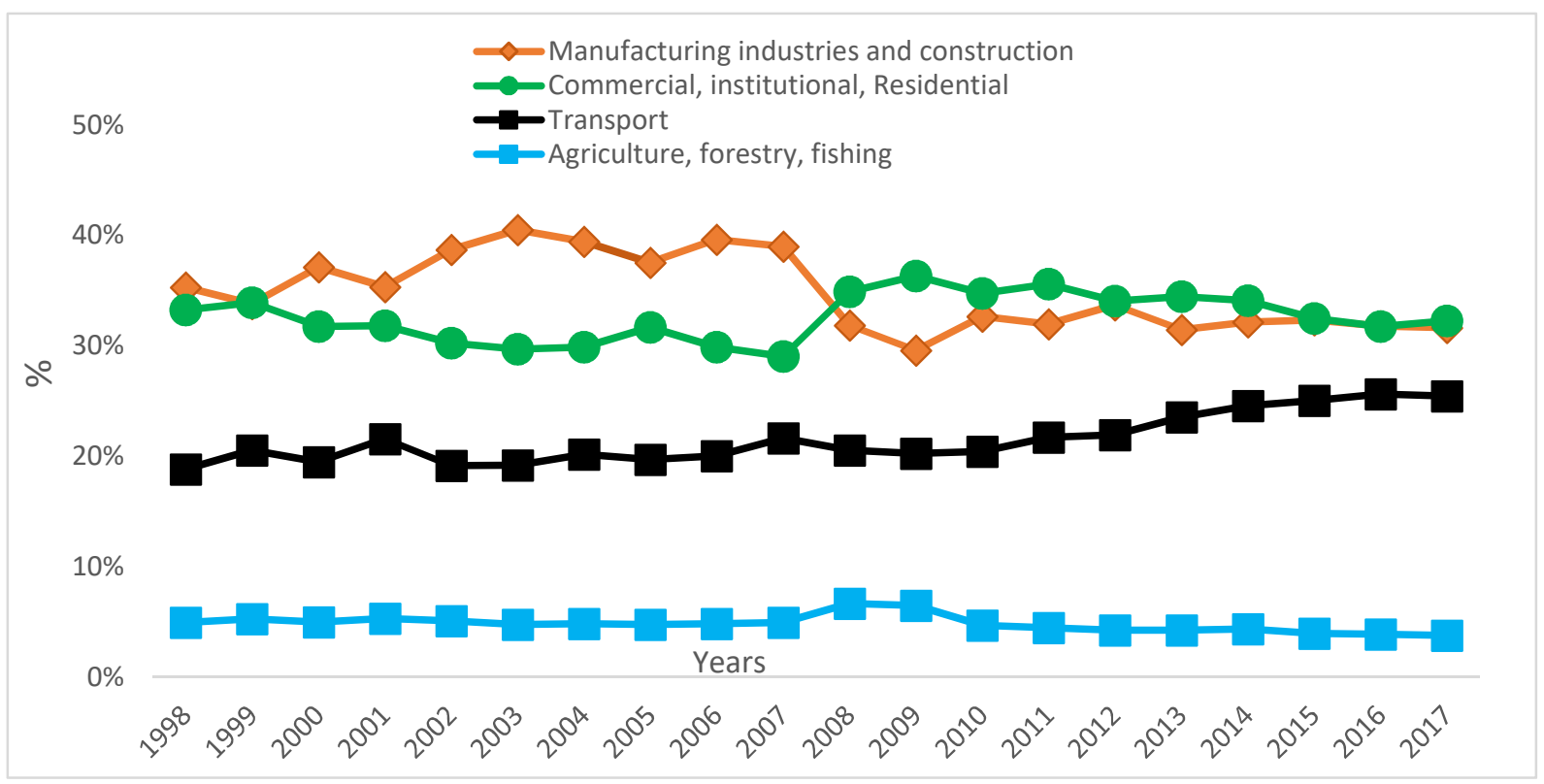

Figure 6. The shares of energy consumption of sectors in Turkey, 1998-2017

The highest increases in primary energy usage in the transportation sector (by $164.2 \%$ ). In contrast, primary energy use from the CIR services (by), manufacturing industries and 
construction and agriculture, forestry, fishing sector increased by $89.6 \%, 75.1 \%$, and $49.5 \%$, respectively, during the period 1998-2017.

\section{Analysis of energy-related GHG emissions}

In this study, we have applied the LMDI method to decompose the changes in the $\mathrm{CO}_{2}$ equivalent emissions of Turkish main four fuel combustion sectors into five effects for the period 1998-2017 by the usage of LMDI. The entire decomposition of $\mathrm{CO}_{2}$ equivalent change emissions is listed in Table 2.

Table 2. Complete decomposition of $\mathrm{CO}_{2}$ emissions changes, kt $\mathrm{CO}_{2}$ eq. (1998-2017).

\begin{tabular}{|c|c|c|c|c|c|c|}
\hline \multirow{2}{*}{ Years } & $\Delta \mathbf{C}_{\text {act }}$ & $\Delta \mathbf{C}_{\text {str }}$ & $\Delta \mathbf{C}_{\text {int }}$ & $\Delta \mathbf{C}_{\text {mix }}$ & $\Delta \mathbf{C}_{\text {emf }}$ & $\Delta \mathbf{C}_{\text {tot }}$ \\
\hline & $\begin{array}{l}\text { Activity } \\
\text { effect }\end{array}$ & $\begin{array}{c}\text { Structure } \\
\text { effect }\end{array}$ & $\begin{array}{c}\text { Intensity } \\
\text { effect }\end{array}$ & $\begin{array}{c}\text { Energy-mix } \\
\text { effect }\end{array}$ & $\begin{array}{c}\text { Emission } \\
\text { factor effect }\end{array}$ & $\begin{array}{l}\text { Total } \\
\text { effect }\end{array}$ \\
\hline 1999-1998 & -10.706 & -3.154 & 11.651 & -4.633 & -1.303 & -8.145 \\
\hline 2000-1999 & 8.440 & -1.186 & 6.897 & 1.451 & -1.079 & 14.524 \\
\hline $2001-2000$ & -36.187 & -109 & 25.841 & -10.110 & 1.999 & -18.566 \\
\hline $2002-2001$ & 19.016 & 766 & -12.974 & 7.094 & -1.048 & 12.854 \\
\hline 2003-2002 & 37.154 & -778 & -23.771 & 1.300 & 638 & 14.543 \\
\hline 2004-2003 & 35.260 & -728 & -26.147 & -236 & -3.343 & 4.806 \\
\hline 2005-2004 & 31.152 & -440 & -29.004 & -600 & 1.256 & 2.364 \\
\hline $2006-2005$ & 13.787 & 1.080 & -2.921 & 212 & -2.095 & 10.062 \\
\hline $2007-2006$ & 34.277 & 921 & -22.745 & -1.330 & 452 & 11.575 \\
\hline $2008-2007$ & 21.913 & 380 & -29.741 & -3.635 & 1.842 & -9.241 \\
\hline 2009-2008 & -29.362 & -4.194 & 32.320 & 5.834 & 606 & 5.203 \\
\hline $2010-2009$ & 28.986 & -4.567 & -23.216 & -574 & -151 & 478 \\
\hline 2011-2010 & 12.445 & -785 & 976 & -2.612 & -526 & 9.499 \\
\hline $2012-2011$ & 8.169 & 4.708 & -4.326 & 1.428 & 595 & 10.575 \\
\hline 2013-2012 & 15.673 & -741 & -15.065 & -6.952 & 196 & -6.889 \\
\hline 2014-2013 & -2.959 & 1.649 & 7.392 & 518 & -688 & 5.912 \\
\hline $2015-2014$ & -15.497 & -1.323 & 36.179 & -360 & -2.231 & 16.768 \\
\hline 2016-2015 & 204 & -2.662 & 11.965 & -534 & -2.486 & 6.486 \\
\hline $2017-2016$ & -2.500 & 3.107 & 13.021 & -4.884 & 2.491 & 11.235 \\
\hline Total & 169.264 & -8.057 & -43.668 & -18.621 & -4.877 & 94.041 \\
\hline
\end{tabular}

The reduction of $\mathrm{CO}_{2}$ emissions results from significant improvements in energy intensity, following by the energy-mix and sectoral energy structure. In general, the energy intensity effect is having a reducing effect on $\mathrm{CO}_{2}$ emissions from all sectors evaluated in this study. 
However, the effect of economic activity is the sole highest significant contribution to increasing $\mathrm{CO}_{2}$ emissions of four primary incineration sector in Turkey (Figure 7).

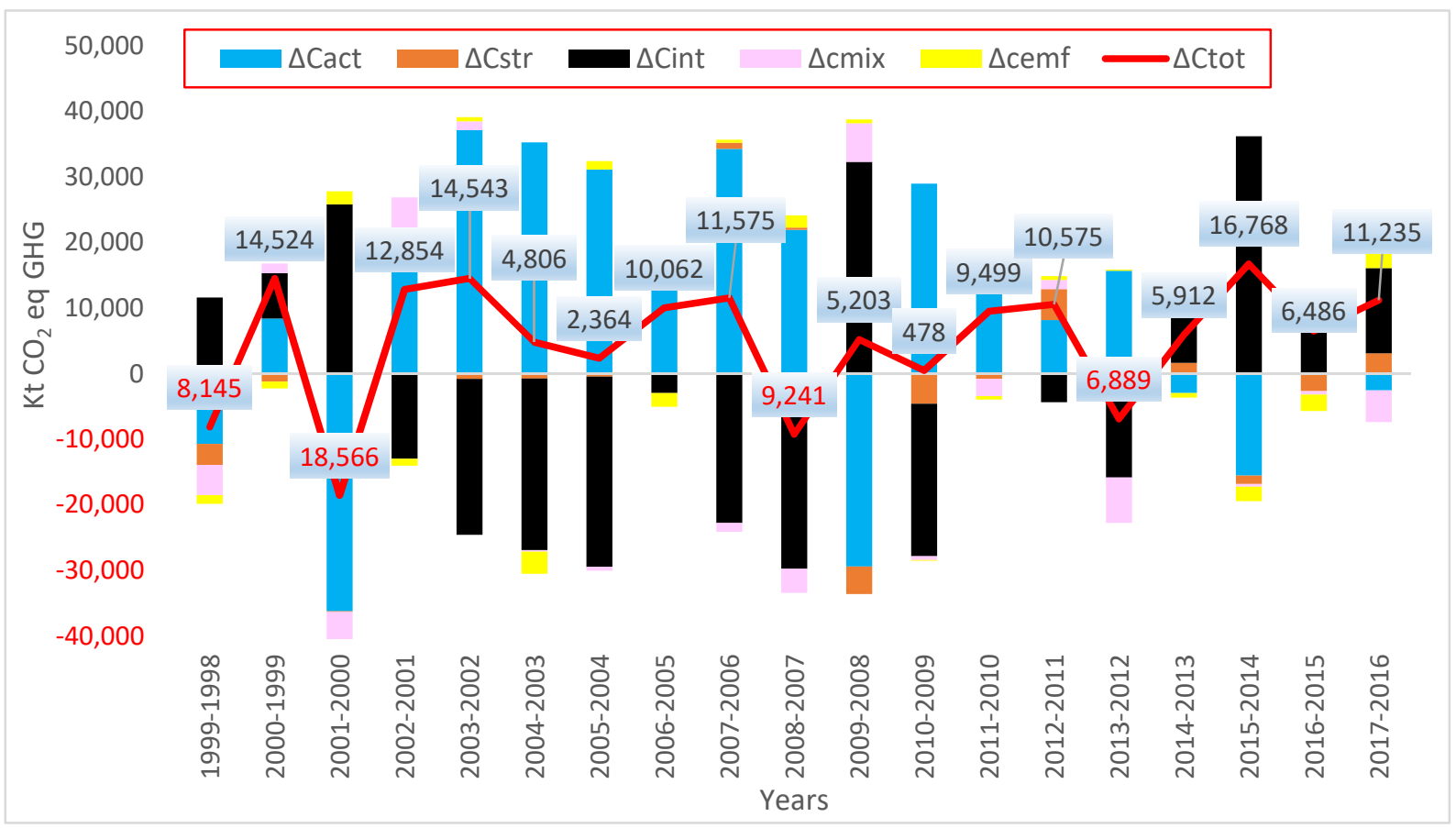

Figure 7. The effects of driving forces on change in GHG emissions, 1998-2017.

\subsection{Economic activity effect:}

GDP represents the country's economic performance and is a measure of national wealth. GDP is a generator of $\mathrm{CO}_{2}$ emissions because energy usage and greenhouse gas are related to economic activity. As a result, GDP growth leads to an increase in greenhouse gas emissions. GDP is, therefore, the main driving force of increased pollution between 1998 and 2017 (GDP rose by 4.8 per cent on average); however economic recession in 1999, 2001, and 2009 GDP decreased by $3.4 \%, 6.0 \%, 4.7 \%$, contributing to a reduction in emissions. The consequences of economic activity affect ( $\Delta \mathrm{Cact}$ ) is the continual increase in emissions of $\mathrm{CO}_{2}$ over the period 1998-2017 (except for the years of economic recession $(1999,2001,2009)$ and GDP declining 
compared to the previous years $(2014,2015$ and 2017). The cumulative effect is a rise of 169.26 Mt, reflecting the absolute value of $179.99 \%$ of the total change in ( $\Delta$ Ctot). Table-3 reveals that the economic activity effect on the overall change of $\mathrm{CO}_{2}$ was found primarily in the manufacturing industries and construction sector and accounted for $+73.8 \mathrm{Mt}$ of GHG emissions. Similarly, the economic activity effect also accounts for $48.1 \mathrm{Mt}$ GHG $\mathrm{CO}_{2}$ equivalent emissions rising in the $\mathrm{CIR}$ sector, $35.4 \mathrm{Mt} \mathrm{CO}_{2}$ equivalent emissions rising in the transport sector, and 12.1 $\mathrm{Mt} \mathrm{CO}_{2}$ equivalent emissions rising in the AFF sector over the period 1998-2017.

Table 3. The effect of economic activity on different sectors, $\mathrm{kt} \mathrm{CO}_{2}$ eq. (1998-2017).

\begin{tabular}{|c|c|c|c|c|c|}
\hline Years & $\begin{array}{c}\text { Manufacturing } \\
\text { industries and } \\
\text { construction }\end{array}$ & $\begin{array}{c}\text { Commercial } \\
\text { institutional } \\
\text { Residential }\end{array}$ & Transport & $\begin{array}{c}\text { Agriculture } \\
\text { Forestry } \\
\text { fishing }\end{array}$ & Total \\
\hline $1999-1998$ & -4.604 & -2.264 & -3.028 & -810 & -10.706 \\
\hline $2000-1999$ & 3.612 & 1.729 & 2.455 & 644 & 8.440 \\
\hline $2001-2000$ & -15.498 & -6.882 & -10.998 & -2.808 & -36.187 \\
\hline $2002-2001$ & 8.284 & 3.359 & 5.887 & 1.486 & 19.016 \\
\hline $2003-2002$ & 17.487 & 6.534 & 10.493 & 2.641 & 37.154 \\
\hline $2004-2003$ & 16.322 & 6.523 & 9.980 & 2.435 & 35.260 \\
\hline $2005-2004$ & 13.663 & 6.243 & 9.061 & 2.184 & 31.152 \\
\hline $2006-2005$ & 6.079 & 2.737 & 4.004 & 967 & 13.787 \\
\hline $2007-2006$ & 15.044 & 6.471 & 10.338 & 2.424 & 34.277 \\
\hline $2008-2007$ & 7.971 & 5.258 & 6.847 & 1.836 & 21.913 \\
\hline $2009-2008$ & -8.547 & -9.304 & -8.780 & -2.731 & -29.362 \\
\hline $2010-2009$ & 8.718 & 9.404 & 8.268 & 2.596 & 28.986 \\
\hline $2011-2010$ & 3.878 & 3.975 & 3.433 & 1.159 & 12.445 \\
\hline $2012-2011$ & 2.626 & 2.625 & 2.529 & 388 & 8.169 \\
\hline $2013-2012$ & 4.951 & 4.750 & 5.714 & 258 & 15.673 \\
\hline $2014-2013$ & -883 & -857 & -1.170 & -49 & -2.959 \\
\hline $2015-2014$ & -4.627 & -4.312 & -6.069 & -489 & -15.497 \\
\hline $2016-2015$ & 60 & 55 & 79 & 10 & 204 \\
\hline $2017-2016$ & -710 & -690 & -983 & -117 & -2.500 \\
\hline Total & $\mathbf{7 3 . 8 2 6}$ & $\mathbf{3 5 . 3 5 3}$ & $\mathbf{4 8 . 0 6 1}$ & $\mathbf{1 2 . 0 2 5}$ & $\mathbf{1 6 9 . 2 6 4}$ \\
\hline
\end{tabular}

Figure 8 also shows the effect of economic activity on the change in GHG emissions. 


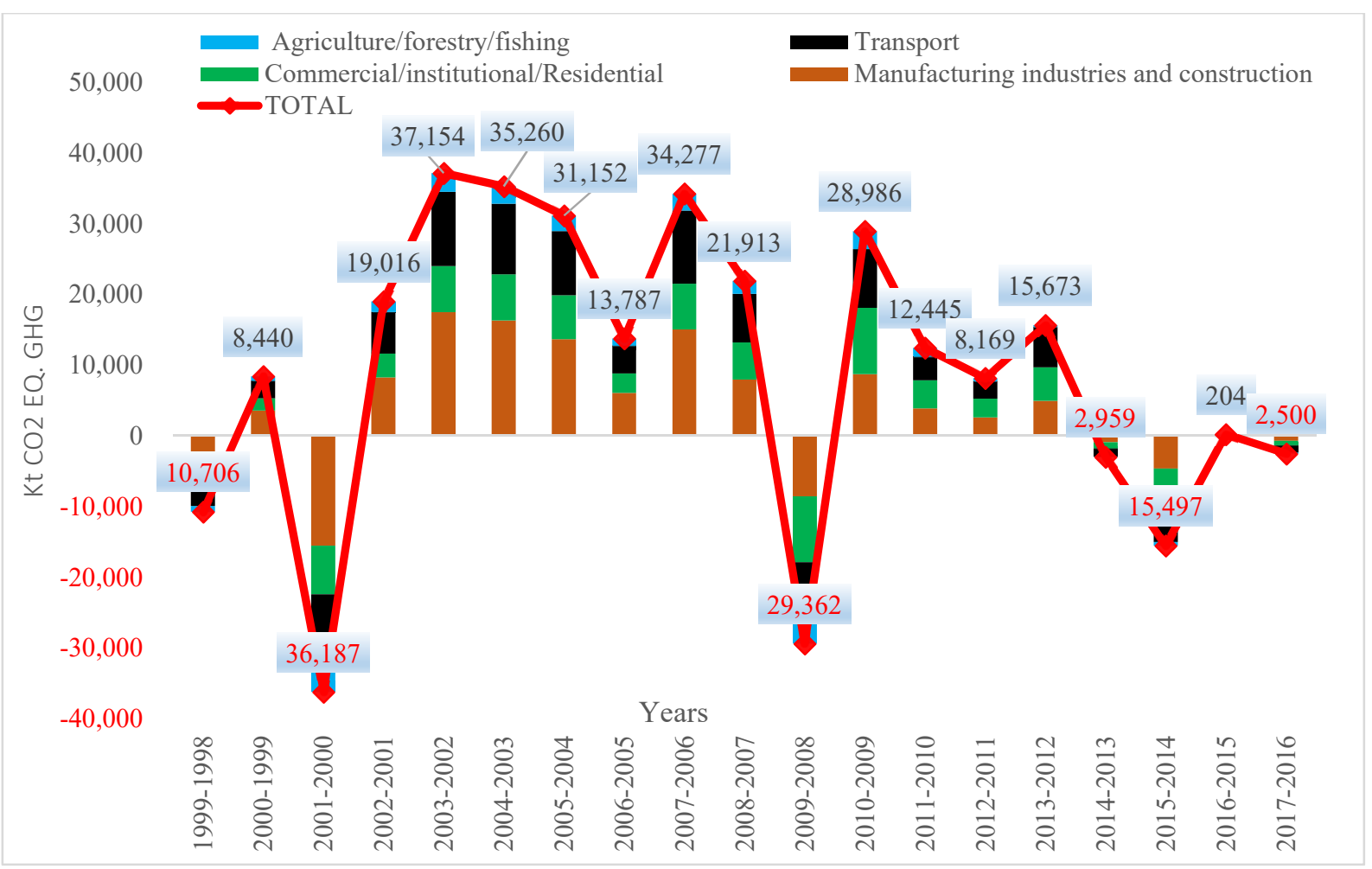

Figure 8 . The effect of economic activity on the change in GHG emissions

\subsection{Sectoral structure effect}

The structural effect is the factor that indicates the change in the value of each sector value within the total economic activity (GDP). From figure 8, it is observed that the share of emissions in the manufacturing sector decreased from $19.8 \%$ to $11.4 \%$, and the agriculture sector decreased from $3.2 \%$ to $1.9 \%$ overall $\mathrm{CO}_{2}$ emissions during the analysis phase, respectively. In contrast, the transport sector and commercial sector were increased from 11.7 $\%$ to $16.1 \%$ and from $10.3 \%$ to $12.0 \%$ respectively.

Table 4 demonstrates that the effect of sectoral structure ( $\Delta$ Cstr), which reduces the emissions of $8.06 \mathrm{Mt} \mathrm{CO}_{2}$ eq., constituting $8.57 \%$ of the absolute value of total change ( $\left.\Delta \mathrm{Ctot}\right)$. 
Table 4. The effect of sectoral structure, $\mathrm{kt} \mathrm{CO}_{2}$ eq. (1998-2017)

\begin{tabular}{|c|c|c|c|c|c|}
\hline Years & $\begin{array}{c}\text { Manufacturing } \\
\text { industries and } \\
\text { construction } \\
\text { (MC) }\end{array}$ & $\begin{array}{c}\text { Commercial } \\
\text { institutional } \\
\text { residential } \\
\text { (CIR) }\end{array}$ & Transport & $\begin{array}{c}\text { Agriculture } \\
\text { forestry } \\
\text { fishing } \\
\text { (AFF) }\end{array}$ & Total \\
\hline $1999-1998$ & -4.655 & 2.155 & 907 & -1.561 & -3.154 \\
\hline $2000-1999$ & -2.877 & -184 & 2.235 & -360 & -1.186 \\
\hline $2001-2000$ & -2.556 & 741 & 2.915 & -1.209 & -109 \\
\hline $2002-2001$ & -2.008 & -929 & 2.343 & 1.360 & 766 \\
\hline $2003-2002$ & 554 & -136 & -839 & -358 & -778 \\
\hline $2004-2003$ & 775 & 132 & -1.172 & -465 & -728 \\
\hline $2005-2004$ & 432 & 69 & -761 & -181 & -440 \\
\hline $2006-2005$ & 2.083 & 283 & 40 & -1.326 & 1.080 \\
\hline $2007-2006$ & 938 & 1.010 & -89 & -937 & 921 \\
\hline $2008-2007$ & -487 & 491 & 438 & -61 & 380 \\
\hline $2009-2008$ & -4.057 & 2.663 & -4.036 & 1.236 & -4.194 \\
\hline $2010-2009$ & 1.103 & -1.984 & -5.218 & 1.531 & -4.567 \\
\hline $2011-2010$ & 4.750 & -1.193 & -2.905 & -1.436 & -785 \\
\hline $2012-2011$ & -341 & 225 & 5.331 & -506 & 4.708 \\
\hline $2013-2012$ & 1.926 & -395 & -1.850 & -421 & -741 \\
\hline $2014-2013$ & 958 & 519 & 233 & -61 & 1.649 \\
\hline $2015-2014$ & -590 & -322 & -690 & -280 & -1.323 \\
\hline $2016-2015$ & 595 & 901 & -3.084 & -1.074 & -2.662 \\
\hline $2017-2016$ & 2.140 & -766 & 1.897 & -165 & 3.107 \\
\hline Total & -1.318 & $\mathbf{3 . 2 8 2}$ & $-\mathbf{4 . 3 0 7}$ & $\mathbf{- 8 . 0 5 7}$ \\
\hline
\end{tabular}

Figure 9 also shows that the sectoral structure has a lower impact on the overall change of $\mathrm{CO}_{2}$ emissions in three sectors; AFF, transport, and MC, while the positive impact only the CIR sector. This effect accounts for the reduction of $-5.7 \mathrm{Mt} \mathrm{CO}_{2}$ eq. GHG emissions in AFF, -4.3 $\mathrm{Mt} \mathrm{CO}_{2}$ eq. GHG emissions in the transport sector, and $-1.3 \mathrm{Mt} \mathrm{CO}_{2}$ eq. GHG emissions in the $\mathrm{MC}$ sector. In contrast, it is accounting for a rising of 3.8 Mt GHG emissions in the CIR sector over the period 1998-2017. 


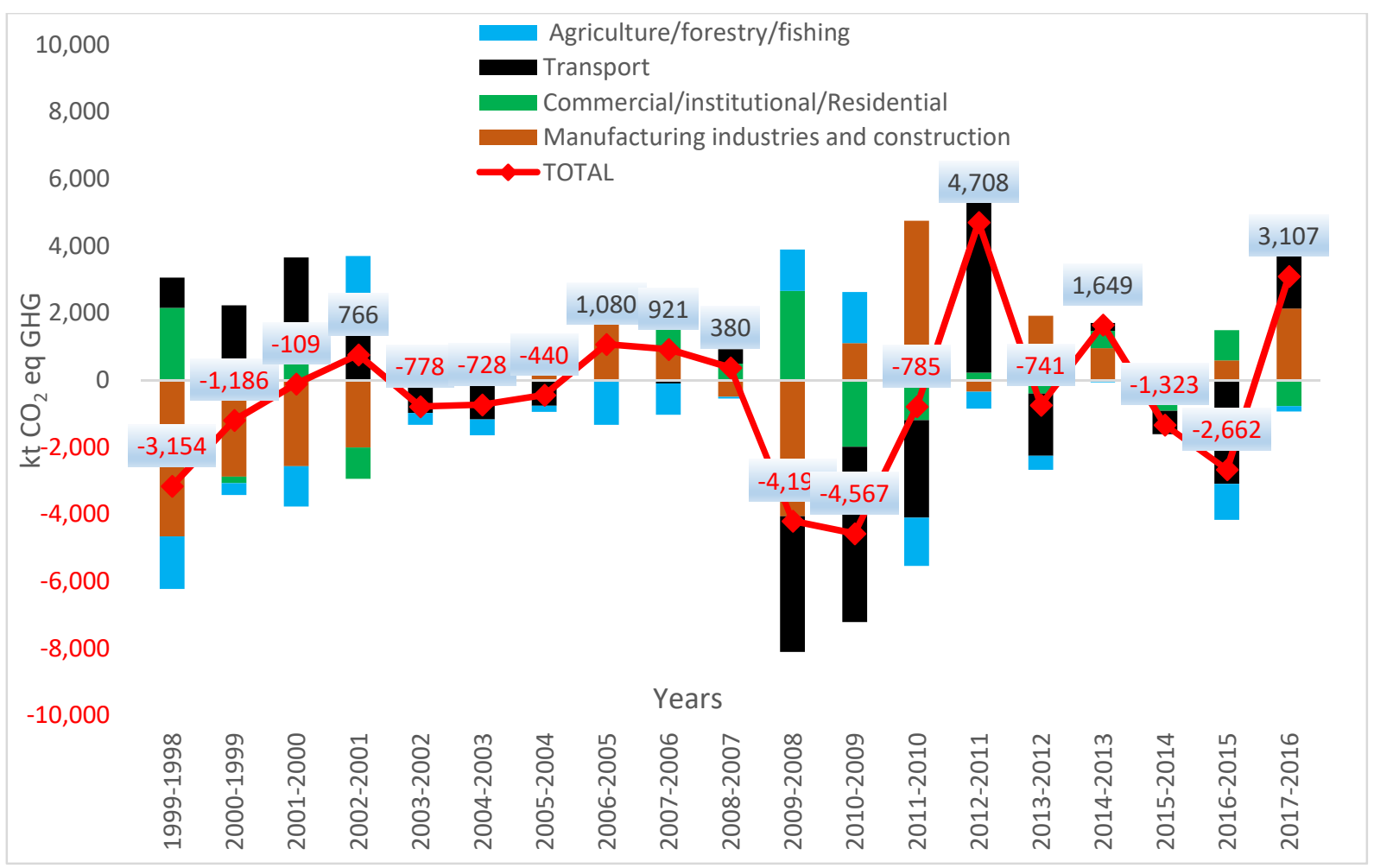

Figure 9. The effect of sectoral structure on change in GHG emissions

\subsection{Sectoral energy intensity effect}

The intensity of energy is measured by the amount of energy per unit output or operation needed, such that the use of lower energy to generate a material decreases the intensity. The intensity effect decreases if the increase in economic output is higher than the increase in energy input. Application of more efficient, effective production techniques, efficient energy management, changes in product mix within or between sub-sectors, and improvements in the quality of material and fuel input reduce the intensity effect. This result means that now more output is produced with less energy, or more production acquired with the same amount of energy used [47]. Many recent academic studies have demonstrated that energy intensity reduction is limited or even reduced the increasing energy-related GHG emissions [6], [12], [23], [25], [48]-[51]. 
Energy intensities for four combustion sectors are presented in Figure 10. It is clear that while the transportation sector has the ultimate energy density, the AFF sector has a minimum from 1998-2017. Moreover, it is noticed that the energy intensity in agriculture fluctuates very much during the period. Finally, in 2017, they reached the level of 1998. Figure 10 illustrates that the energy intensity of the commercial sector has shown a decreasing trend over the period, especially between 1998 and 2014. The energy intensity of the transport sector tends to decrease from 2000 to 2008, the year of the global economic crisis. Especially after the global economic crisis in 2008, the energy intensity trend in the transport sector has been reversed and started to increase so far.

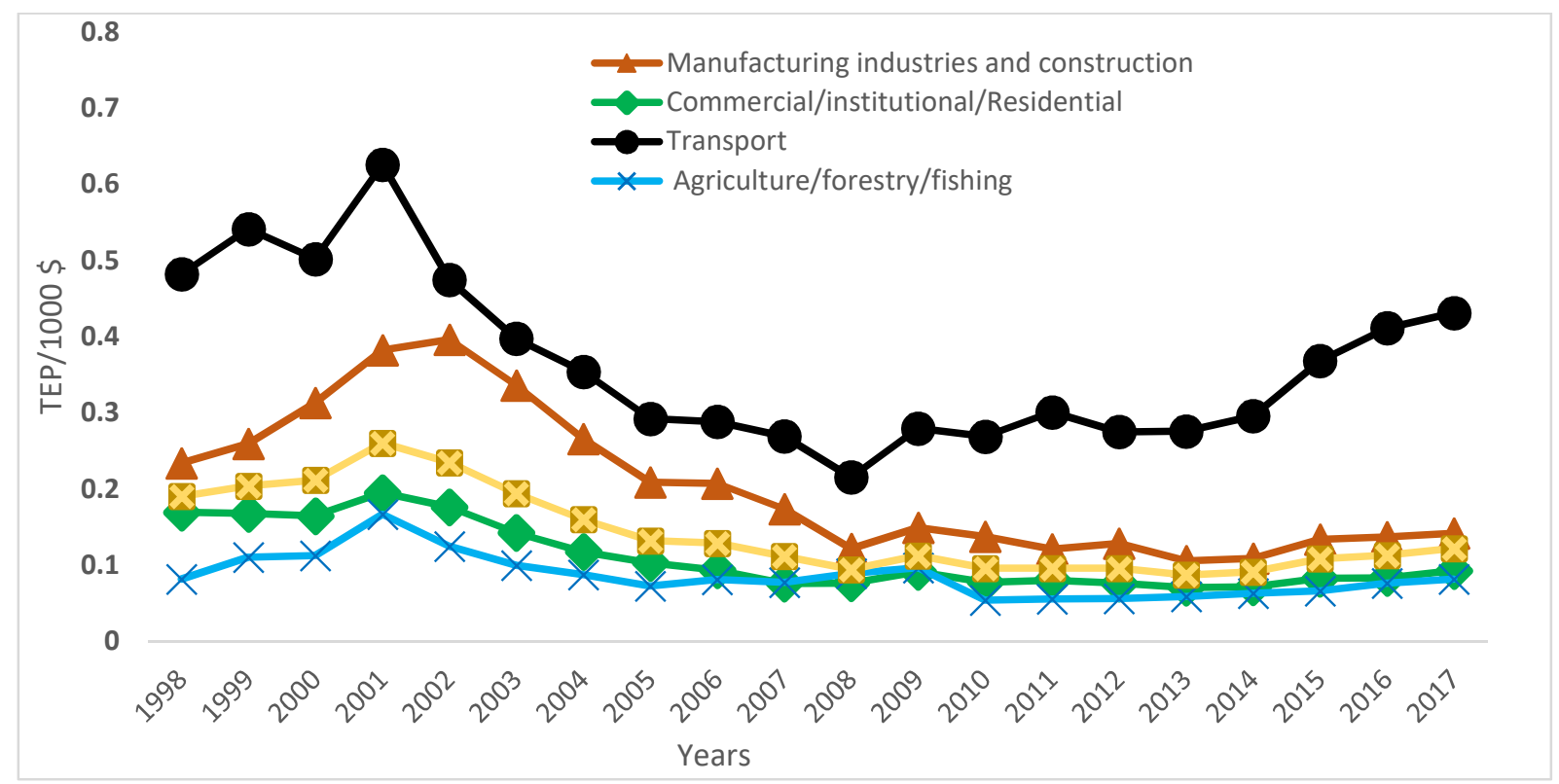

Figure 10 Sectoral energy intensity, 1998-2017

Our findings also indicate that the intensity effect ( $\triangle \mathrm{Cint}$ ) has decreased $\mathrm{CO}_{2}$ emissions in almost years except for 1999-2001 and 2014-2017. The accumulated impact of intensity effect, which reduces the emissions of $43.67 \mathrm{Mt} \mathrm{CO}_{2}$ eq., constituting $46.43 \%$ of the absolute value of the total change ( $\Delta \mathrm{Ctot})$. In other words, the intensity effect plays a significant and active role in reducing $\mathrm{CO}_{2}$ emissions. The impact of the sectoral energy intensity on changes in $\mathrm{CO}_{2}$ equivalent emissions for the period from 1998 to 2017 are presented in Figure 11; It shows that 
even there is a slight increase in 1998-1999, it has a continuously decreasing trend for the period of 2001-2013. The declining tendency may be due to new techniques, innovations, and new tools, followed by the widespread implementation of energy-saving technologies and progress in administration level [14]. Unfortunately, the intensity effect has an increasing tendency from 2015 and so far.

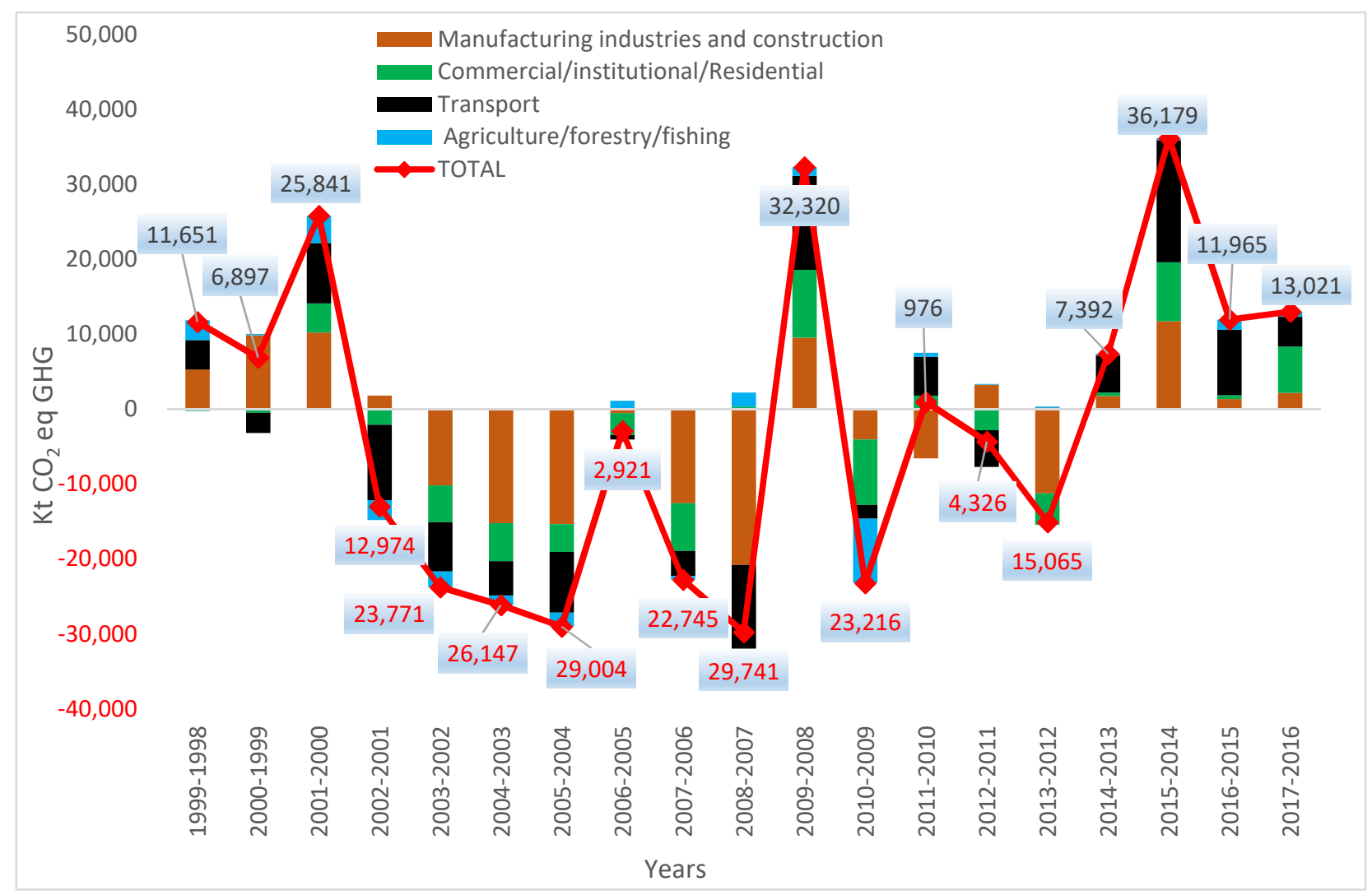

Figure 11. The effect of sectoral energy intensity on change in GHG emissions

\subsection{Energy mix effect}

This effect shows how industries are using available fuels and is calculated by dividing the energy consumption of a fuel type by the total energy consumption of that sector. Figure 12 demonstrates that the impact of energy mix ( $\Delta \mathrm{Cmix})$, which reduces the emission of $18.6 \mathrm{Mt}$ $\mathrm{CO}_{2}$ eq., constituting $19.80 \%$ per cent of the total change ( $\left.\Delta \mathrm{Ctot}\right)$. Figure 12 also shows that the sectoral energy mix impact has a lower impact on the complete change of $\mathrm{CO}_{2}$ emissions in 
three sectors; MC, transport and, AFF, while positive influence only the CIR sector. This effect accounts for the reduction of -27.1 $\mathrm{Mt} \mathrm{CO}_{2}$ eq. GHG emissions in $\mathrm{MC},-1.3 \mathrm{GHG}$ emissions in transport -2.1. GHG emissions in the AFF sector while it accounts for the rising of $+11.8 \mathrm{Mt}$ $\mathrm{CO}_{2}$ eq. GHG emissions in the CIR sector over the period 1998-2017. Solid fuels were accounted for reduction -24.6 $\mathrm{Mt} \mathrm{CO}_{2}$ eq. GHG emissions, and fluid fuels were accounted for a reduction of $-13.9 \mathrm{Mt} \mathrm{CO}_{2}$ eq. $\mathrm{GHG}$ emissions in the manufacturing sector. In contrast, gas and other fuels have a rising energy-mix effect on the same sector.

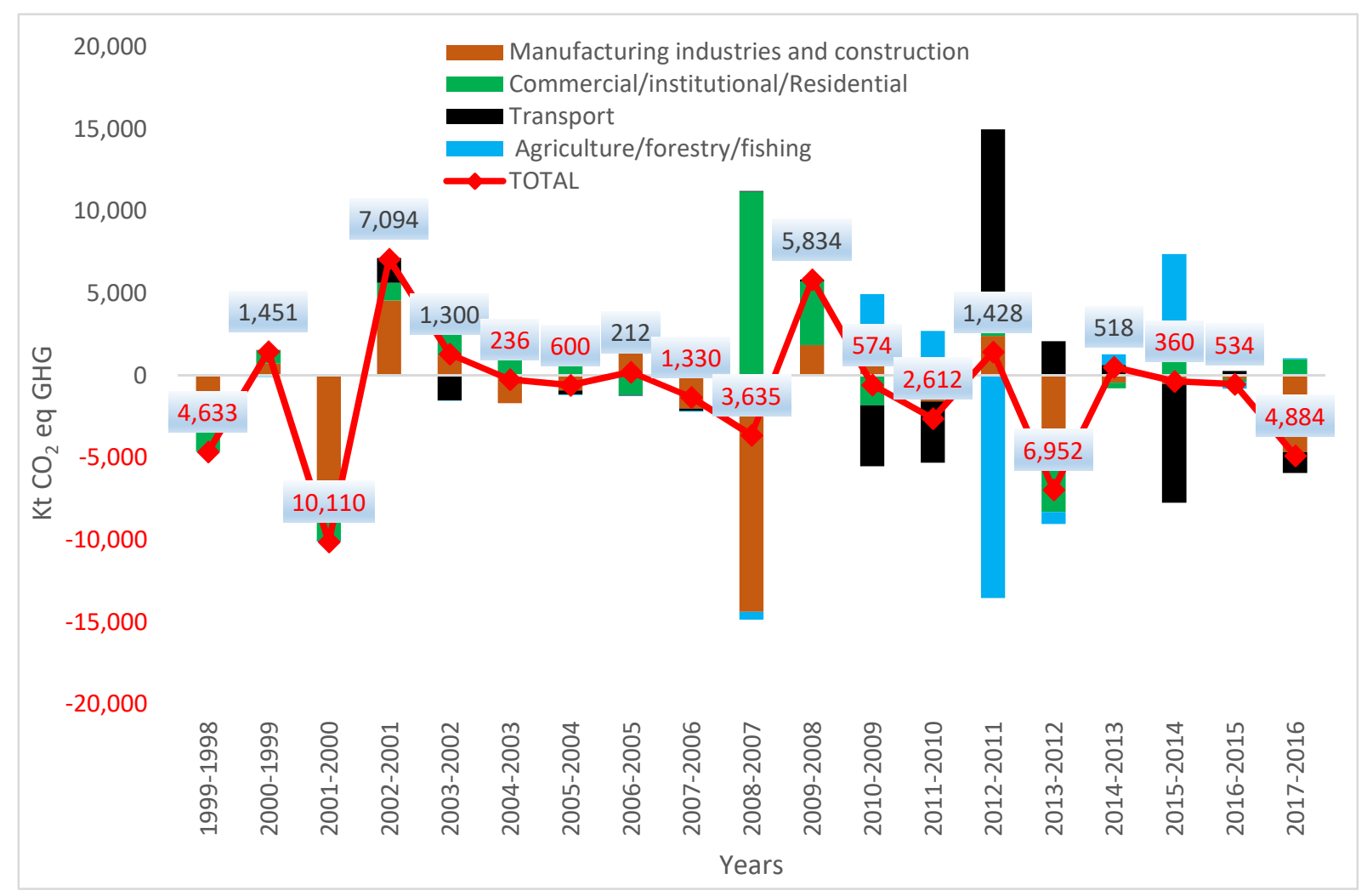

Figure 12. The effect of energy mix on change in GHG emissions

\subsection{Emission factor effect}

Emission factor effect showing the effect of the efficiency of fuels used in the sector on emissions and Figure 13 demonstrates that the emission factor effect ( $\Delta \mathrm{Cemf})$, which reduces the $\mathrm{CO} 2$ eq. emissions only in 10 years in this study. However, the effect of emission factor that reduces the emissions of $4.9 \mathrm{Mt} \mathrm{CO}_{2}$ eq., constituting $5.19 \%$ of the absolute value of the 
total change ( $\Delta \mathrm{Ctot})$. This effect has a little impact on decreasing $\mathrm{CO}_{2}$ eq. emissions in the transportation sector. The emission factor effect $(\Delta \mathrm{Cemf})$ reduces $\mathrm{CO}_{2}$ emissions, especially in two sectors; CIR and MC. This effect accounts for the reduction of $-2.8 \mathrm{Mt} \mathrm{CO}_{2}$ eq. GHG emissions in CIR and -1.4 GHG emissions in the MC sector over the period 1998-2017.

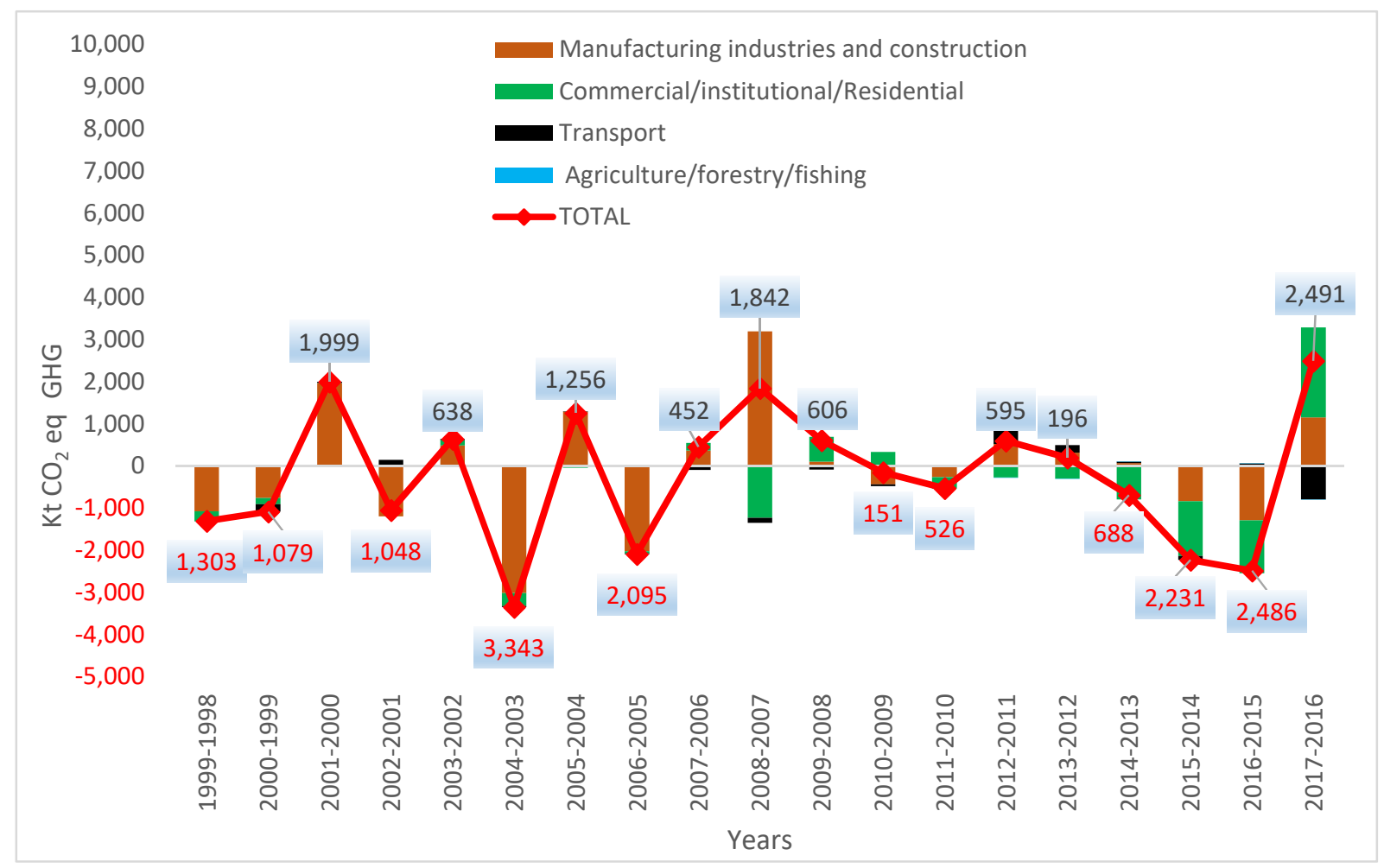

Figure 13. The effect of emission factor on change in GHG emissions

6. Conclusion, discussion and policy recommendations

Since sustainable development and combating climate change has become an essential issue in the 21 st century, the Turkey government would both concentrate on prioritizing economic efficiency and also boost energy conservation and environmental quality. For this purpose, Turkey could implement a lengthy-term low-emissions policy combining climate and energy targets. In this study, the changes in GHG emissions of four combustion sectors in Turkey were analyzed by the LMDI method. It is the complete decomposition method to identify and 
examine the drivers to reach emissions reduction goals and determined to achieve a low-carbon transition for Turkey. Furthermore, there is also a large literature on the study of the energy consumption decomposition and $\mathrm{CO}_{2}$ emissions. However, there is limited application of those techniques to the Turkish economy. There are a few studies which decompose Turkey's energy consumption. While there are at most eight and fewer studies on this subject, the majority of them belong to 2012 and earlier. Such as; Karakaya and Ozçağ (2003) [52] Lise (2006) [24], Ediger and Huvaz (2006) [29] Tunç et al. (2009) [26], Akbostanc1 et al. (2011) [23]. There are only two recent studies on this subject. Rüstemoğlu (2016) [27] has just identified and analyzed the factors that are increasing or decreasing the $\mathrm{CO}_{2}$ emissions for Turkey and Iran over the period 1990-2011. Akbostanci et al. (2018) decomposed and analyzed $\mathrm{CO}_{2}$ emissions of five sectors of the Turkish economy between 1990 to 2013. But this study includes the most recent data, 1998-2017. While the period of the other studies covers an average of 10 years, 20 years was examined in this study. In this context, the measures to be taken by Turkey in these sectors in the implementation of low carbon growth policies and reduction of energy-related emissions for combating climate change are detailed explained. Furthermore, a comprehensive and detailed analysis of GHG emissions of Turkey for four fuel combustion sectors covering $57 \%$ of the energy sector emissions from 1998-2017 were examined, and their contribution to the emission increase was revealed based on the LMDI method. This method makes it possible to differentiate the changes in greenhouse gas emissions on a sectoral basis related to the main effects. For instance; the activity effect, structural effect, intensity effect, energy-mix effect, and emission-factor effects, which are determined as the factors affecting the emission. In this context, the measures to be taken by Turkey in these sectors in the implementation of low carbon growth policies and reduction of energy-related emissions for combating climate change are detailed explained. The key findings of this study could be summarized as follows: 
(1) There is a definite increasing trend between GDP and GHG emissions with different ratios, $138.5 \%$, and $87.5 \%$, respectively. However, after 2009, the proportional increase in economic growth in Turkey was higher than the proportional increase in greenhouse gas emissions and began to experience a divergence between these two variables. Energy demand in Turkey has increased more than GDP growth.

(2) Furthermore, the rise in greenhouse gas emissions is also lower than the rising energy demand. This finding means that the increase in the energy demand of Turkey began to meet from renewable and non-emission sources such as solar, wind. The accelerated legal regulations and increasing investment in renewable energy in the near term in Turkey have an important in the formation of this situation. If renewable energy production policies implement in the following recent years, it would have significant results in reducing greenhouse gas emissions.

(3) Turkey, as a developing country, and has economic growth, demands a high amount of energy, and is carrying out intensive fossil fuel consumption. The empirical results indicated a general increasing tendency in the operating period of $\mathrm{CO}_{2}$ emissions from all four-fuel combustion sectors. Analysis results indicate that economic activity is the primary decisive agent behind the rise in GHG emissions as well as sectoral energy intensity. Namely, the growing economic activity and reducing energy intensity are the significant contributors respectively to increasing and decreasing $\mathrm{CO}_{2}$ emissions of Turkey four fuel combustion industries. The emission-reducing effect of the energy density factor could be seen in a considerable reduction in greenhouse gas emissions of manufacturing and commercial sectors in the period of 1998-2017 as 39.3 and 11.5 Mt. CO2 eq. GHG emissions. Energy structure and emission factor effects would have few impacts on $\mathrm{CO}_{2}$ emission change because of the lack of adequate changes in energy structure during the study period. 
(4) The energy intensity of the Turkish manufacturing and commercial industries decreased respectively by 39.3 and $11.5 \mathrm{Mt} \mathrm{CO}_{2}$ eq. GHG. Unfortunately, there is no progress in the energy intensity of the transport sector, and it causes $10 \mathrm{Mt} \mathrm{CO}_{2}$ eq. emissions increasing.

(5) It is crucial for the improvement of energy efficiency for combustion sectors to be promoted by presenting and applying the latest technology and techniques. Even though energy intensities of only manufacturing and commercial sectors have displayed continual reduction during the 1998-2014 period, the rate of decrease has decelerated and, after 2017, slightly increased. During this time, GHG emissions reduction related to the energy intensity falling has shown that energy intensity could be reduced by improving energy use.

(6) Our analyses emphasized the importance of energy efficiency as the first source of energy. And it exposed the need to establish more favorable conditions for further actions and investment in this area, as in the current economic conditions, which would progress naturally at a slower pace recently. It should be understood that public and private sectors' investment in energy efficiency must be weighted with similarly with any other energy security measures such as renewable incentives, or assured pricing for new nuclear power plants in Turkey.

(7) Energy conservation and efficiency are one of the critical components of Turkey's 2023 national strategic priorities and energy policies, such as ensuring the protection of energy demand, decreasing the external dependency threats, protecting the environment, and raising the effectiveness of combating climate change [53]. From 2001 through 2008, there was a favorable declining energy intensity for four energy-intensive industries. After the global economic crisis in 2008 , the tendency of energy intensity of manufacturing, commercial, and agricultural sectors have stayed on the same level. In contrast, the energy intensity of the transport sector reversed and has started to tremendous increase so far. Policymakers should investigate and try to find and solve the reasons behind these most critical problems. Moreover, 
Turkey could set more ambitious measurable energy efficiency objectives in the transport, agricultural, and other energy-intensive sectors.

(8) Sustainable development and combating climate change has become an essential issue in the last decades. Turkey's and other developing countries' governments should focus on achieving economic efficiency, increase energy savings, and improve the quality of the environment. For this intention, Turkey and other developing countries should pursue a longterm low-emissions policy that combines energy, environment, and climate targets, offering more economic inducement for energy efficiency investments in housing, transportation sectors.

(9) The economic structures have changed toward consuming fewer electricity services, and shifting the product mix with high value-added products must be provided to achieve a lowcarbon Turkey.

(10) As the installation of capacity-efficient production equipment is added, it would be crucial to increase industry efficiency and reducing fuel consumption and GHG emissions. According to the finding obtained in this study, the above-mentioned proposed policies would have powerful effects on reducing emissions in Turkey.

(11) The energy mix effect performs the second leading position in reducing $\mathrm{CO}_{2}$ emissions and accounted for reduction -18.6 Mt GHG emissions. Most of this reduction set in the manufacturing industry (reduction of -27.1 Mt g emissions).

In this study, the reduction of emissions is of great importance for many researchers, and scientists in countries intend to combat climate change and transition to low carbon or green economy. For this purpose, it is crucial to determine the key drivers that affect the change of emissions and to determine the effect of these drivers on the sectors' emissions reduction. For this purpose, the changes for GHG emissions from four energy-intensive sectors in Turkey have been analyzed by the LMDI approach. This method displays that the effect of energy intensity could be the first primary determining factor in GHG emissions. Since its effect has a reducing impact on $\mathrm{CO}_{2}$ emissions from all sectors evaluated in this study and also there is a reduction 
of $\mathrm{CO}_{2}$ emissions (43, $6 \mathrm{Mt}$ ) resulted from notable developments in energy intensity during the period for 1998-2017. It is following by the energy-mix (18.6 Mt) and sectoral energy structure (8.1 Mt). The study, therefore, calls for policies aimed at reducing the energy intensity of companies in the manufacturing industries and construction sector, Commercial/institutional/Residential industries so that Turkey can make use of industrial development without having to cause more GHG emissions. Furthermore, we also could propose that Turkey and other developing countries should continue its attempts to raise the share of renewable energy sources and add nuclear energy to its energy mix to reduce its reliance on energy import. They also would optimize the use of natural resources and combat climate change under the enrichment of the national energy mix topic. Moreover, it is explained what this model does and measures to be taken on a sector basis.

\section{References}

[1] IPCC, “Climate Change 2014 Synthesis Report,” IPCC, Switzerland, 2015.

[2] TURKSTAT, "Greenhouse Gas Emissions Statistics, 1990-2017 (press release,2019)," 2019. [Online]. Available: http://www.turkstat.gov.tr/PreHaberBultenleri.do?id=30627.

[3] TURKSTAT, "Turkish Greenhouse gas inventory report 1990-2017," TURKSTAT, Ankara, 2019.

[4] OECD, OECD Environmental Performance Reviews: Turkey, 2019. OECD, 2019.

[5] B. W. Ang, "The LMDI approach to decomposition analysis: A practical guide," Energy Policy, vol. 33, no. 7, pp. 867-871, 2005.

[6] M. Zhang, X. Liu, W. Wang, and M. Zhou, "Decomposition analysis of CO2 emissions from electricity generation in China," Energy Policy, vol. 52, pp. 159-165, 2013.

[7] J. Wang, S. He, Y. Qiu, N. Liu, Y. Li and Z. Dong, "Investigating driving forces of aggregate carbon intensity of electricity generation in China," Energy Policy, vol. 113, no. July 2017, pp. 249-257, 2018.

[8] B. Gu, X. Tan, Y. Zeng and Z. Mu, "CO2 Emission Reduction Potential in China's Electricity Sector: Scenario Analysis Based on LMDI Decomposition,” Energy Procedia, vol. 75, pp. 2436-2447, 2015.

[9] M. Zhang, H. Mu, Y. Ning, and Y. Song, "Decomposition of energy-related CO2 emission over 1991-2006 in China," Ecol. Econ., vol. 68, no. 7, pp. 2122-2128, 2009.

[10] C. Wang, J. Chen, and J. Zou, "Decomposition of energy-related CO2 emission in China: 1957-2000," Energy, vol. 30, no. 1, pp. 73-83, 2005.

[11] Y. Song, J. B. Huang, and C. Feng, "Decomposition of energy-related CO2 emissions in China's iron and steel industry: A comprehensive decomposition framework," Resour. Policy, vol. 59, no. March, pp. 103-116, 2018.

[12] W. Zhang, K. Li, D. Zhou, W. Zhang, and H. Gao, "Decomposition of intensity of energy-related CO2 emission in Chinese provinces using the LMDI method," Energy Policy, vol. 92, no. 2016, pp. 369-381, 2016.

[13] Y. Tian, Q. Zhu, and Y. Geng, "An analysis of energy-related greenhouse gas emissions in the Chinese iron and steel industry," Energy Policy, vol. 56, pp. 352-361, 2013.

[14] X. Xu, T. Zhao, N. Liu, and J. Kang, "Changes of energy-related GHG emissions in China: An empirical analysis from sectoral perspective," Appl. Energy, vol. 132, no. 
2014, pp. 298-307, 2014.

[15] M. Li, "Decomposing the change of $\mathrm{CO} 2$ emissions in China: A distance function approach," Ecol. Econ., vol. 70, no. 1, pp. 77-85, 2010.

[16] E. Hatzigeorgiou, H. Polatidis, and D. Haralambopoulos, "CO 2 emissions in Greece for 1990-2002: A decomposition analysis and comparison of results using the Arithmetic Mean Divisia Index and Logarithmic Mean Divisia Index techniques," Energy, vol. 33, no. 3, pp. 492-499, 2008.

[17] H. Achour and M. Belloumi, "Decomposing the influencing factors of energy consumption in Tunisian transportation sector using the LMDI method," Transp. Policy, vol. 52, pp. 64-71, 2016.

[18] S. Paul and R. N. Bhattacharya, "CO2 emission from energy use in India: A decomposition analysis," Energy Policy, vol. 32, no. 5, pp. 585-593, 2004.

[19] N. V. Emodi and K. J. Boo, "Decomposition analysis of CO2 emissions from electricity generation in Nigeria," Int. J. Energy Econ. Policy, vol. 5, no. 2, pp. 565573, 2015.

[20] J. M. Cansino, A. Sánchez-Braza, and M. L. Rodríguez-Arévalo, "Driving forces of Spain's CO2 emissions: A LMDI decomposition approach,” Renew. Sustain. Energy Rev., vol. 48, pp. 749-759, 2015.

[21] D. González and M. Martínez, "Decomposition analysis of CO2 emissions in the Mexican industrial sector," Energy Sustain. Dev., vol. 16, no. 2, pp. 204-215, 2012.

[22] A. K. Sumabat et al., "Decomposition analysis of Philippine CO2 emissions from fuel combustion and electricity generation," Appl. Energy, vol. 164, pp. 795-804, 2016.

[23] E. Akbostanci, G. I. Tunç, and S. Türüt-Aşik, "CO2 emissions of Turkish manufacturing industry: A decomposition analysis," Appl. Energy, vol. 88, no. 6, pp. 2273-2278, 2011.

[24] W. Lise, "Decomposition of CO 2 emissions over 1980-2003 in Turkey," Energy Policy, vol. 34, no. 14, pp. 1841-1852, 2006.

[25] E. Akbostanc1, G. İ. Tunç, and S. Türüt-Aş1k, "Drivers of fuel based carbon dioxide emissions: The case of Turkey," Renew. Sustain. Energy Rev., vol. 81, no. July 2017, pp. 2599-2608, 2018.

[26] G. Ipek Tunç, S. Türüt-Aşik, and E. Akbostanci, "A decomposition analysis of CO2 emissions from energy use: Turkish case," Energy Policy, vol. 37, no. 11, pp. 46894699, 2009.

[27] H. Rüstemoğlu, "Environmental costs of economic growth : Determinants of CO2 emissions in Turkey and Iran," pp. 2151-2168, 2016.

[28] S. Shao, L. Yang, C. Gan, J. Cao, Y. Geng, and D. Guan, "Using an extended LMDI model to explore techno-economic drivers of energy-related industrial CO2 emission changes: A case study for Shanghai (China)," Renew. Sustain. Energy Rev., vol. 55, pp. 516-536, 2016.

[29] V. S.. Ediger and O. Huvaz, "Examining the sectoral energy use in Turkish economy (1980-2000) with the help of decomposition analysis," Energy Convers. Manag., vol. 47, no. 6, pp. 732-745, 2006.

[30] J. Chontanawat, P. Wiboonchutikula, and A. Buddhivanich, "An LMDI decomposition analysis of carbon emissions in the Thai manufacturing sector," Energy Reports, vol. 6, pp. 705-710, 2019.

[31] G. Trotta, "Assessing energy efficiency improvements and related energy security and climate benefits in Finland: An ex-post multi-sectoral decomposition analysis," Energy Econ., vol. 86, 2020.

[32] J. Yu, C. Shao, C. Xue, and H. Hu, "China's aircraft-related CO2 emissions:

Decomposition analysis, decoupling status, and future trends," Energy Policy, vol. 138, 
no. January, p. 111215, 2020.

[33] Y. Bu, E. Wang, J. Bai, and Q. Shi, "Spatial pattern and driving factors for interprovincial natural gas consumption in China: Based on SNA and LMDI," J. Clean. Prod., vol. 263, p. 121392, 2020.

[34] J. Zhang, Z. Fan, Y. Chen, J. Gao, and W. Liu, "Decomposition and decoupling analysis of carbon dioxide emissions from economic growth in the context of China and the ASEAN countries," Sci. Total Environ., vol. 714, p. 136649, Apr. 2020.

[35] W. Zhang, X. Tang, G. Yang, and D. Zha, "Decomposition of CO2 emission intensity in Chinese MIs through a development mode extended LMDI method combined with a production-theoretical approach," Sci. Total Environ., vol. 702, 2020.

[36] L. Wang, Y. Wang, H. He, Y. Lu, and Z. Zhou, "Driving force analysis of the nitrogen oxides intensity related to electricity sector in China based on the LMDI method," $J$. Clean. Prod., vol. 242, no. X, 2020.

[37] Y. Qian, H. Cao, and S. Huang, "Decoupling and decomposition analysis of industrial sulfur dioxide emissions from the industrial economy in 30 Chinese provinces," $J$. Environ. Manage., vol. 260, no. September 2019, 2020.

[38] Y. Song, M. Zhang, and C. Shan, "Research on the decoupling trend and mitigation potential of CO2 emissions from China' s transport sector," Energy, vol. 183, pp. 837843, 2019.

[39] D. Fang, P. Hao, and J. Hao, "Study of the influence mechanism of China's electricity consumption based on multi-period ST-LMDI model," Energy, vol. 170, pp. 730-743, 2019.

[40] F. Li et al., "Changing patterns and determinants of transportation carbon emissions in Chinese cities," Energy, vol. 174, pp. 562-575, 2019.

[41] S. Jiang, Y. Zhu, G. He, Q. Wang, and Y. Lu, "Factors influencing China's nonresidential power consumption: Estimation using the Kaya-LMDI methods," Energy, p. 117719, 2020.

[42] L. Jiang, S. He, X. Tian, B. Zhang, and H. Zhou, "Energy use embodied in international trade of 39 countries: Spatial transfer patterns and driving factors," Energy, vol. 195, p. 116988, 2020.

[43] B. W. Ang, "Decomposition analysis for policymaking in energy: Which is the preferred method?," Energy Policy, vol. 32, no. 9, pp. 1131-1139, 2004.

[44] IPCC, 2006 IPCC Guidelines for National Greenhouse Gas Inventories, vol. 2 Energy, no. 4. Japan: Institute for Global Environmental Strategies (IGES), 2006.

[45] Republic of Turkey Ministry of Environment and Urbanization, "Seventh National Communication of Turkey under the UNFCCC," Ankara, 2018.

[46] Republic of Turkey Ministry of Energy and Natural Resources (MENR)., "Balance Sheets 1998-2017," Ankara.

[47] G. Du, C. Sun, X. Ouyang, and C. Zhang, "A decomposition analysis of energy-related CO2 emissions in Chinese six high-energy intensive industries," J. Clean. Prod., vol. 184, pp. 1102-1112, 2018.

[48] C. Wang, J. Chen, and J. Zou, "Decomposition of energy-related CO2 emission in China: 1957-2000," Energy, 2005.

[49] M. Wang and C. Feng, "Decomposing the change in energy consumption in China's nonferrous metal industry: An empirical analysis based on the LMDI method," Renewable and Sustainable Energy Reviews, vol. 82. Elsevier Ltd, pp. 2652-2663, 01Feb-2018.

[50] B. Lin and R. Tan, "Sustainable development of China's energy intensive industries: From the aspect of carbon dioxide emissions reduction," Renew. Sustain. Energy Rev., vol. 77, no. February, pp. 386-394, 2017. 
[51] C. Feng, J. B. Huang, and M. Wang, "The driving forces and potential mitigation of energy-related CO2 emissions in China's metal industry," Resour. Policy, vol. 59, pp. 487-494, Dec. 2018.

[52] M. Karakaya, E. Özçağ, “Evaluation of Kyoto Protocol from Turkey’s Perspective and Analysis of the Determinants of CO2 Emission with Decomposition Method (in Turkish)," in VII.METU ERC International Conference in Economics, 2003.

[53] Republic of Turkey Ministry of Energy and Natural Resources (MENR), National energy efficiency action plan (NEEAP) 2017-2023. Ankara, 2018. 